\title{
GEOGLIFOS Y TRÁFICO PREHISPÁNICO DE CARAVANAS DE LLAMAS EN EL DESIERTO DE ATACAMA (NORTE DE CHILE)
}

\author{
GEOGLYPHS AND PREHISPANIC LLAMA CARAVAN TRAFFIC IN THE \\ ATACAMA DESERT (NORTHERN CHILE)
}

\author{
Luis Briones*, Lautaro Núñez** y Vivien G. Standen***
}

\begin{abstract}
Este estudio aporta nuevos antecedentes empíricos, resultado de las excavaciones de cuatro campamentos de uso transitorio y dos entierros humanos, asociados a sitios con geoglifos, ubicados a lo largo de una ruta caravanera prehispánica de $150 \mathrm{~km}$, que conectó a los oasis de Pica con la costa del océano Pacífico. Puesto que la mayoría de estos sitios se encuentra en territorios desérticos sin recursos, asociados a contextos tales como coprolitos de llamas y hojas de maíces, argumentamos que fueron componentes directos del tráfico caravanero. Esta ruta estuvo vinculada al intenso tráfico macrorregional de larga distancia por donde circulaban bienes económicos y suntuarios procedentes de los más diversos ambientes (selva-altiplano-oasis-pampacosta). Las seis dataciones de radiocarbono, obtenidas de los contextos excavados, indicarían que, si bien la mayoría de los geoglifos de la transecta de estudio fueron elaborados durante el período del Desarrollo Regional (900-1.450 años d.C.), ciertas rutas transdesérticas ya estaban en uso, al menos desde el Arcaico Tardío (1.300 años a.C.), por parte de cazadores, pescadores y recolectores.
\end{abstract} absolutas.

Palabras claves: geoglifos, caravanas de llamas, rutas de tráfico prehistórico, campamentos transitorios, dataciones

This study brings new empirical evidence, resulting from the excavation of four transitory camp sites and two human burials associated with geoglyphs, and found along a prehispanic caravan path of $150 \mathrm{~km}$ long, connecting the Pica oasis with the Pacific coastal ocean in the Atacama desert in northern Chile. Since the majority of these sites are found in resourceless desertic areas and are associated to contexts such as llama coprolites and corn leaves, we argue that these sites were direct components of caravan trafficking. This route was linked to an intensive long distance macro-regional traffic associated with the circulations of economic and sumptuary goods from diverse origins, including the selva, altiplano, oasis, pampa and coast. Radiocarbon dates obtained at the excavations indicate that even though most of the geoglyphs were created during the Desarrollo Regional period (900-1,450 yrs. A.D.) some transdesertic routes were already used, from at least the Late Archaic Period (1,300 B.C.) by hunters, fishers and gatherers.

Key words: Geoghlyphs, llama caravans, prehistoric traffic, transitory campsites, geoglyph dating.

En la última década se ha enfatizado el rol del movimiento caravanero prehispánico, a partir de las tempranas propuestas de los años sesenta, oportunidad en que las relaciones entre asentamientos fijos y de trayecto (paskanas), rutas, ritualidad e intervención macrorregional, dieron lugar a explicaciones no difusionistas de diversas modalidades de contactos interétnicos y espaciales al interior de redes de complementariedad (Berenguer 1994, 2004; Núñez 1976, 1985 a y b; Núñez y Dillehay 1979). El modelo caravanero ha ampliado su marco espacial de análisis, hasta el sur peruano (Gordillo 1992), altiplano aledaño (Flores y MacQua- rrie 1994) y área circumpuneña (Nielsen 1997-98; Yacobaccio 1978). Así, es cada vez más necesario documentar, con la mayor variedad posible de indicadores arqueológicos y etnográficos, aquellos espacios donde la penetración caravanera es más explícita, especialmente en despoblados sin continuidad ocupacional, con asentamientos-ejes que acceden a recursos diferenciados a través de rutas de larga distancia sostenidas por una intensa ritualidad, tal como se observa en el desierto de Atacama, norte de Chile.

La analogía observada entre conjuntos de geoglifos, localizados a lo largo de la transecta que

\footnotetext{
* Departamento de Antropología, Universidad de Tarapacá, Casilla 6 D, Arica, Chile. lbriones@uta.cl

** Instituto de Investigaciones Arqueológicas, Universidad Católica del Norte, San Pedro de Atacama, Chile. Inunez@netline.cl

*** Centro de Investigaciones del Hombre en el Desierto; Departamento de Antropología, Universidad de Tarapacá, Casilla 6 D,

Arica, Chile.vstanden@uta.cl
} 
conectó los oasis de Pica con la costa del océano Pacífico (Figuras 1 y 2), asociados a rutas y paskanas (refugios caravaneros), han permitido postular un trazado vial que articuló a los diversos ambientes del desierto. Hasta ahora, la correlación entre estilos de geoglifos, fases temporales y filiaciones culturales más específicas, se ha planteado tentativamente a partir de comparaciones estilísticas y diseños homologables identificados en cerámica y textiles, derivados de contextos arqueológicos regionales. Estas aproximaciones han correlacionado a la mayoría de los geoglifos con el período del Desarrollo Regional (900-1.450 años d.C.) (Briones y Chacama 1987; Muñoz y Briones 1998; Núñez y Briones 1967). Sin embargo, se han establecido algunas aproximaciones temporales más tempranas, aún tentativas, de geoglifos de "círculos" asociados a asentamientos formativos, como el caso de Pircas (Núñez 1984), incluyendo diseños únicos y de alta complejidad como el personaje del cerro Unita, correspondiente a un icono antropomorfo con cabeza radiada, posiblemente también de data formativa (Núñez et al. 1997; Santoro y Dauelsberg 1985). Así, se puede hipotetizar que los geoglifos se desarrollaron, en secuencia entre los 400 años a.C. hasta el tiempo Inca, con un clímax estilístico durante el período del Desarrollo Regional antes referido.

La transecta de estudio (Figuras 1 y 2 ) se enmarca en una cubierta geográfica estéril sin ríos o rutas naturales, característico del desierto arreico, cuyos antecedentes geológicos lo enmarcan por el este con la formación Altos de Pica, sobre los 4.000 $\mathrm{msm}$, desde donde se tiene una amplia visión semiaérea de aproximadamente $150 \mathrm{~km}$ hacia el oeste. Destacan los oasis de Pica y Matilla, la pampa del Tamarugal, el salar de Pintados y la cordillera de la Costa.

La cordillera de la Costa presenta una proyección montañosa hacia el interior del continente en una amplitud que alcanza los $60 \mathrm{~km}$, seccionando parcialmente la pampa del Tamarugal en los salares de Pintados por el norte y Bellavista por el sur. Esta geomorfología ofrece un continuo espacial que conecta el borde occidental del piemonte con el borde oriental de la cordillera costera, con mínimos recursos de agua subterránea, que se traducen en aguadas o pozos de utilidad para las travesías por el desierto de condiciones hiperáridas. Esto explicaría la locación de Cerros Pintados con sus impresionantes geogli- fos, vinculados directamente a aguadas, convirtiéndose en puntos de convergencia de rutas y senderos desde los más diversos extremos de la región tarapaqueña (Figuras 1 y 2).

Desde la perspectiva del caravanero alto-andino, del pasado y presente, se trata de espacios extensos y abiertos, de alta visibilidad. La elección de determinados cerros y colinas a lo largo de la transecta, con el objeto de transferir allí la representación de iconos insertos en la ritualidad caravanera, implicó sacralizar el paisaje en donde los geoglifos marcaban el carácter de cerro sagrado, de aquel espacio que, constituyendo un pasaje de tránsito obligado, era a su vez un pasaje que se marcaba ceremonialmente. Precisamente, donde termina la "mesada" altiplánica y comienza el paisaje de oasis de las tierras bajas, observamos que los "pasos" se van ritualizando con apachetas y "casitas", alusivas al ceremonial de viajeros y caravaneros (Núñez 1976). Por ejemplo, en la mama-apacheta de Cala Cruz y las de Chilín-Chilín (inmediatamente al sur), los aymaras actuales que participan en estas travesías indican que, a través de rogativas específicas, piden no solo "esperanzas por lo que les viene por delante", sino además "encargan la casa y el ganado" a la pachamama (Santos Quispe y Maximiliano Mamani, comunicación personal $2000^{2}$; ver también van Kessel 1976). Estas percepciones y emociones de los que fueron jóvenes caravaneros radicados en Pica parecen no ser tan distintas a las manifestaciones de la ritualidad prehispánica, especialmente en sus expresiones del imaginario más susceptible de ser modificado y adicionado permanentemente como lo es el arte rupestre (Galdames 1990).

\section{Metodología de Trabajo}

Para avanzar en la problemática en torno a las dataciones del arte rupestre registrado en superficies sedimentarias, se optó por el estudio de la transecta Pica-Pintados-Alto Barranco (Figuras 1 y 2). Ésta representa un conjunto de evidencias, que favorecen una mejor comprensión del tráfico caravanero entre los oasis y el litoral, tales como: presencia de geoglifos en despoblados estériles, con estilos clave compartidos desde la cabecera de los oasis de Pica hasta la costa; asociación de geoglifos a rutas y paskanas; contextos culturales de cementerios en los oasis, estaciones intermedias y costa aledaña; testimonios etnográficos del mane- 


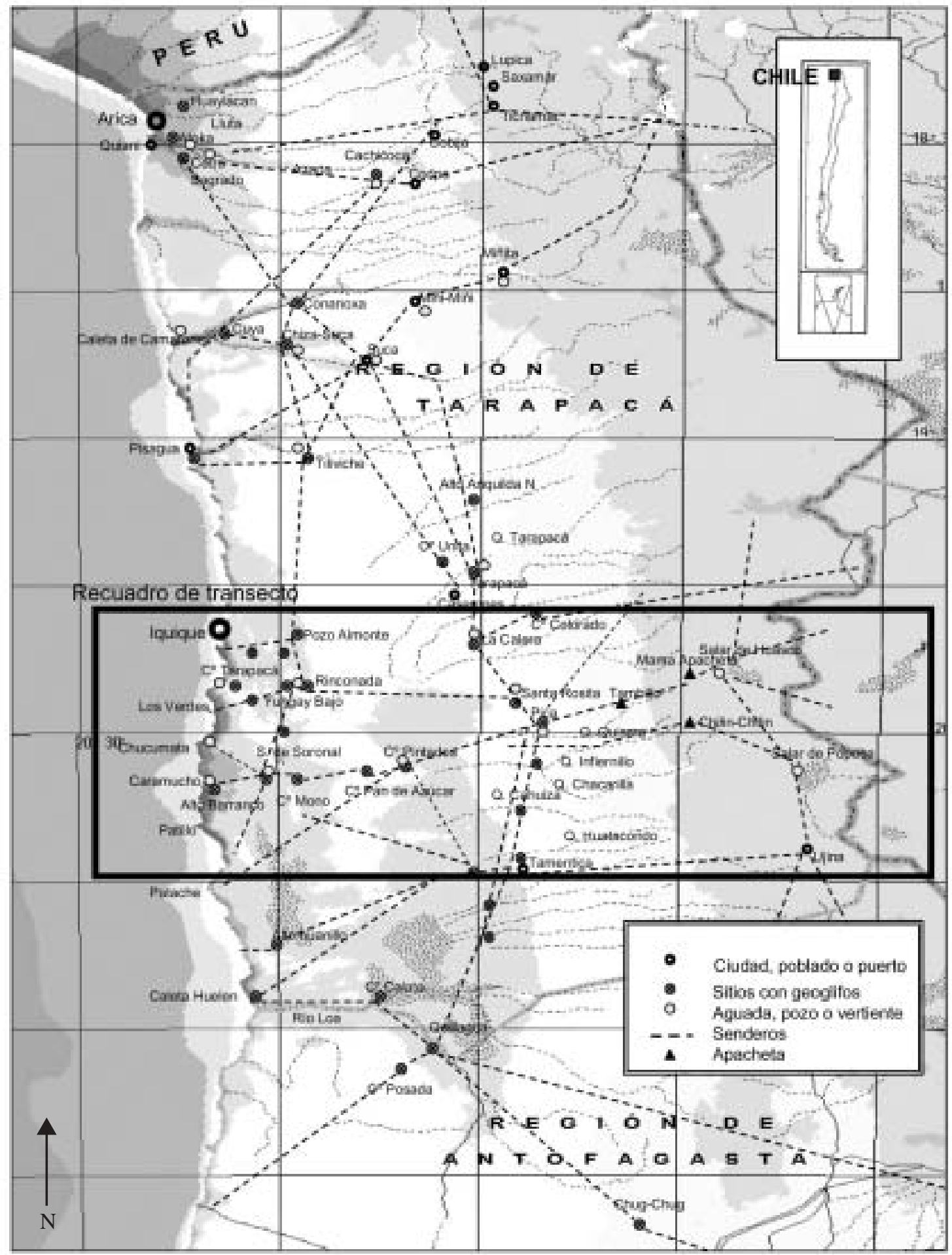

Figura 1. Registro de los principales sitios con geoglifos y aguadas, citados en el texto (norte de Chile).

Record of the main sites associated with geoglyphs and water resources in northern Chile cited in the text. 


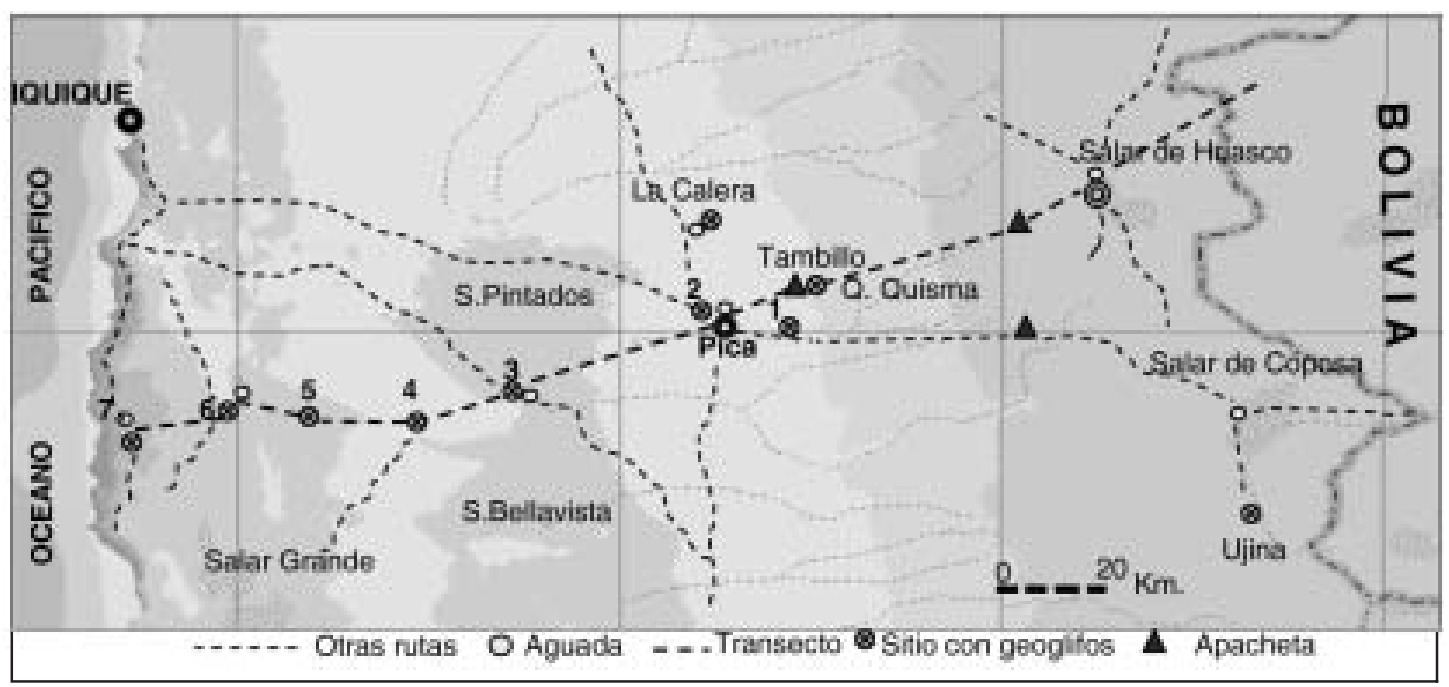

Figura 2. Detalle de la transecta de estudio: Oasis de Pica-Cerros Pintados-Alto Barranco. Sitios: 1. El Salto; 2. Santa Rosita; 3. Cerros Pintados; 4. Cerro Pan de Azúcar; 5. Cerro Mono; 6. Salar Soronal; 7. Alto Barranco.

Detailed depiction of the study transect: Oasis de Pica-Cerros Pintados-Alto Barranco. Sites: 1. El Salto; 2. Santa Rosita; 3. Cerros Pintados; 4. Cerro Pan de Azúcar; 5. Cerro Mono; 6. Salar de Soronal; 7. Alto Barranco.

jo caravanero entre el altiplano meridional y los oasis piqueños (Núñez 1985 a y b).

El estudio se orientó a obtener dataciones absolutas de las rutas asociadas a estructuras y geoglifos, a partir de restos orgánicos considerados componentes directos del tráfico regional prehispánico. Otros intentos recientes para fechar geoglifos con métodos absolutos arrojaron resultados contradictorios (Clarkson 1998), ya que algunos geoglifos de estilos supuestamente correspondientes al Desarrollo Regional arrojaron dataciones más tempranas de lo esperado (Dorn 1989) ${ }^{3}$.

La metodología adoptada en este estudio se basa en: (a) identificación de depósitos y fogones en contextos de actividades domésticas, tales como refugios o paskanas, ubicados en las rutas de la transecta en estudio; (b) identificación de coprolitos de llamas y residuos orgánicos, en los senderos, espacios dedicados al forrajeo y entorno de los geoglifos; (c) identificación y análisis de entierros humanos, ubicados al interior o cerca de geoglifos, tal como los documentados en la serranía de la pampa salitrera (Bollaert 1860 [1975]) y en una tumba aislada y saqueada, localizada en el medio de un panel con geoglifos en el valle de Azapa $^{4}$; (d) identificación de cementerios ubicados cerca de estructuras y geoglifos, con cierta probabilidad de asociación, tal como los documentados en Santa Rosita y salar de Soronal.
Puesto que la mayoría de estos registros se encuentra en territorios desérticos sin recursos, se debería admitir que fueron componentes directos del tráfico caravanero, en distintos periodos de tiempo aún no bien determinados. En esta dirección, la prospección realizada en 1999 por los autores se orientó a revisar unidades arqueológicas a lo largo de la transecta en estudio, del orden de los $150 \mathrm{~km}$, que integra a los oasis del complejo PicaTarapacá y sus conexiones con las tierras altas y el litoral aledaño, respectivamente (Figura 1). Se trata de establecer una correlación más directa entre los eventos ocupacionales que ocurrieron en el entorno de los geoglifos, ya que, mientras éstos no se puedan datar directamente, esta estrategia propuesta parece ser por ahora la más adecuada.

Las conexiones ritualísticas entre petroglifos, pictografías, corrales y apachetas dan cuenta de diversas rutas que convergen desde el altiplano a los oasis de Pica-Tarapacá (Figura 1), articulando a los oasis y el litoral, pero reflejándose en las tierras bajas, esta vez bajo la ritualidad de los geoglifos, cuya máxima frecuencia y representatividad guarda relación con los asentamientos del complejo Pica-Tarapacá, cuya élite mantenía sus territorios abiertos a las conexiones multiétnicas, de acuerdo a la interdigitación de los indicadores cerámicos (p. ej., cerámica Huruquilla en los oasis de Pica) (Núñez 1985a). 


\section{Descripción de los Sitios Arqueológicos Prospectados en la Transecta de Estudio}

\author{
El Salto $(82.3)^{5}($ UTM 479040 E - 7729532 N; \\ $1.460 \mathrm{msm})$
}

Está localizado a unos $6 \mathrm{~km}$ al sureste del oasis de Pica, en un sector de pampa que bordea por el sur el curso inferior de la quebrada de Quisma (Figura 1). Los geoglifos están distribuidos entre lomas arenadas, situación que contribuye a su escasa visibilidad, y fueron elaborados con técnica extractiva o de raspado. Una ruta asociada, tipo "rastrillo" (múltiples huellas paralelas), conecta los oasis piqueños con el altiplano del salar de Coposa y Ujina. Además esta ruta se conecta con el conjunto de apachetas de Cala Cruz y Chilín-Chilín, al sur del salar de Huasco (Figuras 1 y 2$)^{6}$.

En el panel mejor conservado, se identifica un par de geoglifos en contacto directo con la ruta referida. Una de las figuras se describe como "franja con una secuencia de figuras romboidales distribuidas verticalmente" $(257.1)^{7}$; mide $15 \mathrm{~m}$ de largo por $2 \mathrm{~m}$ de ancho y el vértice superior está marcado con un montículo de piedras, aunque sin llegar a constituir una apacheta (Clarkson y Briones 2001). Una figura similar, pero de mayor magnitud y complejidad, se localiza a nivel de pampa en Alto Tarapacá Norte. Ambos geoglifos muestran la misma orientación norte-sur y se asocian directamente a las rutas caravaneras y a figuras de "círculos". Estos diseños son reiterativos y generalmente se emplazan en el plano horizontal de las pampas, muy próximos a los senderos, antes de que éstos enfrenten una cuesta. Podrían vincularse al mensaje simbólico de la cercanía a recursos de agua, que en este caso marca la proximidad a los oasis de Pica.

Santa Rosita $(82.2)^{5}$ (UTM 462600 E - 7732949 $\mathrm{N} ; 1.320 \mathrm{msm}$ )

En el distrito arqueológico de Santa Rosita (relacionado con un pukio u oasis) se identifican: cementerio, geoglifos, rutas y estructuras (Núñez 1966). En la actualidad el cementerio presenta sectores muy saqueados, no obstante, algunos contextos funerarios no disturbados, fueron excavados por Niemeyer $(1959,1963)$, demostrando su temporalidad tardía, preincaica. De acuerdo a las dataciones del complejo Pica-Tarapacá (Núñez 1966), se esperaría que las evidencias arqueológicas podrían ubicarse entre los 900 a 1.450 años d.C.

En Santa Rosita, se identifican múltiples senderos, generándose una verdadera red vial (Figura 1). A unos $50 \mathrm{~m}$ al noroeste del cementerio, se observan rutas que pasan por el pie y a media pendiente de la colina; uno de estos es el que une Pica con Tarapacá por el norte; otros hacia el oeste, internándose en la cordillera de la costa por el abra de Cerros Pintados, Gallinazos, Rinconada y Peña Grande, accediendo a diversas caletas de la costa desértica, como Bajo Molle, Los Verdes, Chucumata, Caramucho y otras en el ámbito de la desembocadura del río Loa (Figuras 1 y 2).

Los geoglifos de Santa Rosita son un importante hito iconográfico y referencial, debido a la presencia de la figura "rombo escalonado", típico por su amplia distribución regional y su alta frecuencia. El panel principal se concentra a unos 150 $\mathrm{m}$ al norte de la aguada y del cementerio, con seis "rombos escalonados" realizados en técnica extractiva y orientados al sur. Las figuras de gran proporción alcanzan hasta los $900 \mathrm{~m}^{2}$ cada una. El patrón del rombo más clásico se describe como "rombo escalonado irregular, de cuatro cuerpos por lado, "cabeza" y "base", de lados cóncavos; "brazos" rectangulares, unidos en sus vértices" (222.0) ${ }^{7}$. Esta cualidad formal los define como los más representativos, entre la gran variedad de rombos que se distribuyen desde la quebrada de Camarones por el norte, hasta el entorno del río Loa por el sur. Así, los rombos de la transecta Pica-Alto Barranco son segmentos iconográficos de una amplia red de interacción, dando cuenta de las conexiones caravaneras preincaicas entre los oasis, valles occidentales y el río Loa medio y superior, bajo una ritualidad que sería una extensión del complejo Pica-Tarapacá.

\section{Cerros Pintados}

El distrito arqueológico de Cerros Pintados comprende un amplio sector de laderas de un cordón que forma parte de la cordillera de la costa, flanqueando el borde oeste del salar de Pintados. Es un sitio de características relevantes para la arqueología sudamericana, visitado por Plagemann y Bollaert en el siglo XIX y numerosos investigadores, despertando interés para la comprensión de las relaciones entre caravaneros y el tráfico de larga distancia, en un medio ambiente de característi- 
cas desérticas extremas (Núñez 1976). En este sitio se han identificado sobre 60 paneles, que reúnen un total de 420 figuras. Cubren un área estimada de $50.000 \mathrm{~m}^{2}$, en una franja de $3 \mathrm{~km}$ de longitud, siendo el de mayor magnitud conocido en el norte de Chile. Recientemente hemos identificado dos campamentos (CP-2 y CP-3) asociados a vestigios de afloramientos de agua, en el sector sur del plano del salar, a $200 \mathrm{~m}$ al este de los geoglifos (Figuras 3 y 4); además de un conjunto de senderos y rutas caravaneras que conectan los oasis de Pica con la costa.

Cerros Pintados 2 (CP-2) ${ }^{5}$ (UTM 430358 E $7720046 \mathrm{~N}$; $990 \mathrm{msm}$ )

Corresponde a un campamento de uso transitorio, con fogones expuestos y fragmentación cerámica del Desarrollo Regional Tardío. En excavaciones previas $(1985)^{8}$, se realizaron dos tests estratigráficos (de $50 \times 50 \mathrm{~cm}$ ) en un sector con restos orgánicos expuestos, cuya base limitaba con el techo de un depósito inferior de ceniza compactada y uniforme, con escasos restos culturales. El campamento presenta además un relleno diferenciado de pozo de agua, fogones, lascas de uso expeditivo y los senderos que bordean la paskana.

El primer muestreo, permitió obtener carbones asociados a desechos de alimentación y cerámica alisada (Estrato II, bajo la costra salina superficial), dispuestos sobre el depósito de ceniza. La fecha obtenida (Muestra 1, Figura 4) fue de $8.840 \pm 90$ años a.p. (Beta-9204), la cual obviamente no tiene relación con los componentes culturales del sitio. Para contrastar con una segunda muestra, se fecharon carbones del Estrato II, inmediatamente sobre el mismo depósito con ceniza y sedimento quemado en una matriz compactada con sales (Muestra 2, Figura 4). La muestra se asocia a restos de conchas del Pacífico, cerámica café estriada del complejo Pica-Tarapacá y a un componente formativo con superficies negras pulidas y bordes evertidos, que recuerdan especímenes de Caserones, el que a su vez se vincula con eventos homólogos de San Pedro de Atacama. Por otro lado, la muestra de carbón se registró intercalada en concreciones del salar, reactivados por la evaporación de las napas subterráneas del depósito inferior arcaico. Esta vez la datación fue de $6.125 \pm 95$ a.p. (SI-6866) ${ }^{9}$. Con estas dos dataciones tan tempranas, se aceptó una superposición de ocupaciones, entre una arcaica y otra caravanera sobreimpuesta.
Para los efectos de dilucidar el tiempo de ocupación en la paskana, a través del presente proyecto, se volvió a fechar el depósito en cuestión con una muestra de carbones obtenida de la base del Estrato II. El resultado fue de $9.066 \pm 80$ a.p. (Beta150709) calibrada en 10.000 - 9.960 a.p. (un sigma) (Figura 4, Muestra 3).

Dada la consistencia de estas dataciones tempranas, se propone a modo de hipótesis, que grupos humanos arcaicos se instalaron en torno a los recursos de aguas subterráneas y forraje del borde sur de la cuenca del salar de Pintados. Aunque se destaca que a excepción de la ceniza compactada, no hay ningún rasgo o artefacto cultural de filiación arcaica. Muy posteriormente habrían ocupado el mismo lugar las caravanas llameras, ya que hasta ahora no se conocen evidencias consistentes entre cazadores-recolectores arcaicos y diseños de geoglifos. Expectativas de esta naturaleza podrían admitir que sería posible identificar expresiones embrionarias, toda vez que a través de la tecnología de petroglifos ha sido posible definir el estilo circumpuneño Puripica-Kalina, en contextos arcaicos tardíos (Berenguer 1998a; Núñez 1982).

Por ahora estudiamos la posible contaminación que pudo ocurrir en carbones tardíos (contemporáneos a los caravaneros del Desarrollo Regional) al absorber por el efecto de capilaridad, evaporación y concentración ascendente de sales y carbón diluido desde los niveles inferiores correspondiente a las ocupaciones arcaicas.

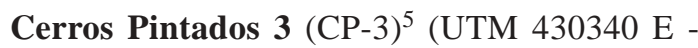
$7720130 \mathrm{~N}$; $990 \mathrm{msm}$ )

Para lograr una mayor precisión en torno a la temporalidad de CP-2, se procedió a examinar la superficie de otro campamento caravanero, localizado a $50 \mathrm{~m}$ al sur del precedente y con similares atributos. Aquí, en CP-3, se identificaron dos recintos pircados, áreas de fogones y talleres (Figuras 5 y 6). Se excavó bajo un sello salino un depósito con densas concentraciones de huesos de pescados y marlos de maíces (Figura 7); el cual parece haber cumplido un rol ceremonial, toda vez que, en los dos test excavados, aparecen restos de plumas de guacamayos ${ }^{10}$ y un "object top like" (Bird 1943) comunes en los cementerios Pica 1 y 8 (identificados como tapones de ceramio botelliformes), demostrándose así una conexión con los oasis de Pica. 


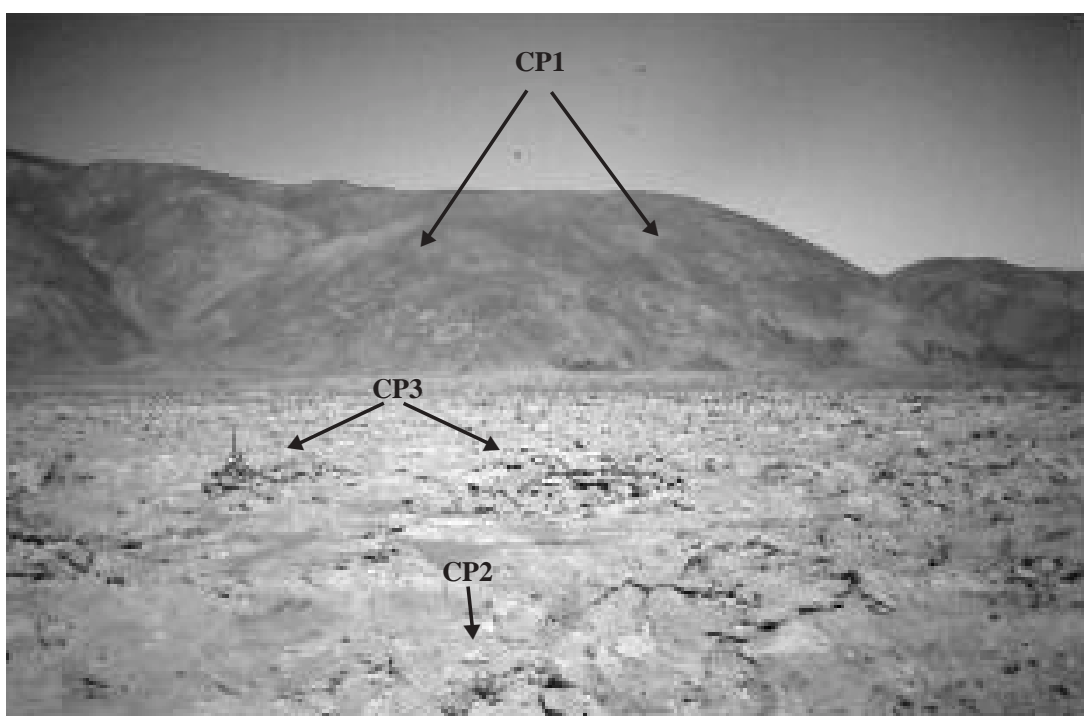

Figura 3. Vista panorámica de los geoglifos de Cerros Pintados-1 (CP1), desde los campamentos CP-2 y CP-3.

Panoramic view of Cerros Pintados-1 (CP1) geoglyphs from campsites CP-2 and CP-3.

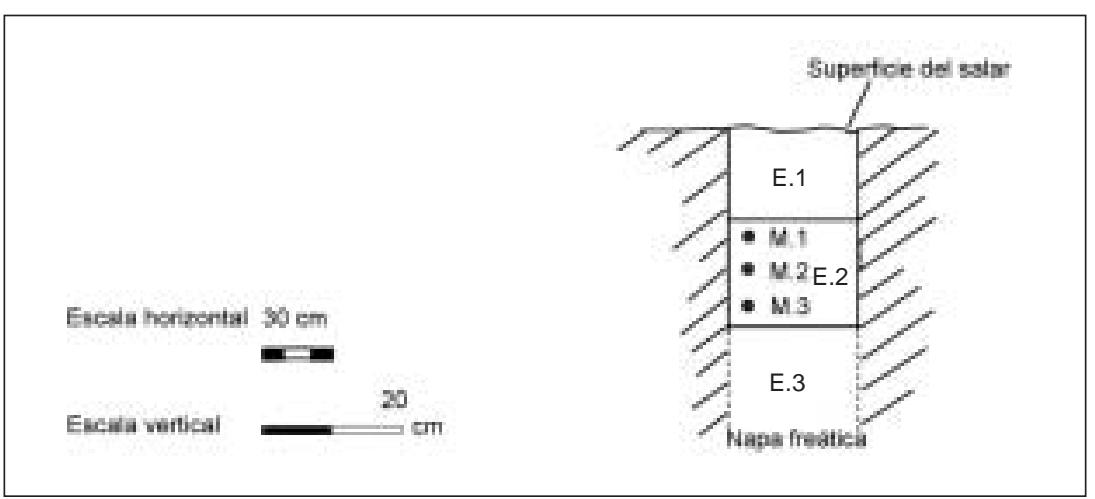

Figura 4. Corte cronoestratigráfico (test 1) del campamento Cerros Pintados-2. E 1. Superficie erosionada por salar. Restos culturales entre sales evaporadas; E 2. Depósito cultural. Restos orgánicos y cerámica entre sales evaporadas (Muestra 1: $6.125 \pm 95$ a.p., Muestra 2: $8.840 \pm 90$ a.p., Muestra 3: $9.066 \pm 80$ a.p.); E 3. Depósito con ceniza fina muy compacta. No excavado.

Chronostratigraphic cut (test 1) of campsite Cerros Pintados-2. E 1. Eroded salar surface. Cultural remains embedded in nitrate soil; E 2. Cultural stratum. Organic remains and pottery in nitrate soil (Sample 1: 6,125 \pm 95 B.P., Sample 2: 8,840 \pm 90 B.P., Sample 3: 9,066 \pm 80 B.P.); E 3. Stratum with compacted ashes. No excavated.

Uno de estos depósitos, semisubterráneo y sellado, contenía abundantes restos de esquelones de pescado del Pacífico y marlos de maíz (Figura 7). Se debe considerar que la distancia entre el sitio y la costa es de $40 \mathrm{~km}$, equivalentes a dos jornadas días mínimas, por lo que es posible un acceso continuo al litoral. Se identificaron además coprolitos de llamas y cerámica preinca del complejo PicaTarapacá. Un marlo fue datado en $970 \pm 50$ años a.p. (Beta-150710) calibrada en 990-1.180 años
d.C. (un sigma) correspondiente al Desarrollo Regional (Figura 6).

La presencia de: (1) plumas de guacamayo, (2) un tapón de madera, y (3) y conchas del Pacífico (Figura 6), podría sugerir que se trata de ofrendas rituales dispersadas entre los restos alimenticios procedentes tanto de los oasis como del litoral, en el marco de las rogativas de los caravaneros, para lo cual seleccionaban aquellos bienes más emblemáticos de los ejes del movimiento giratorio com- 


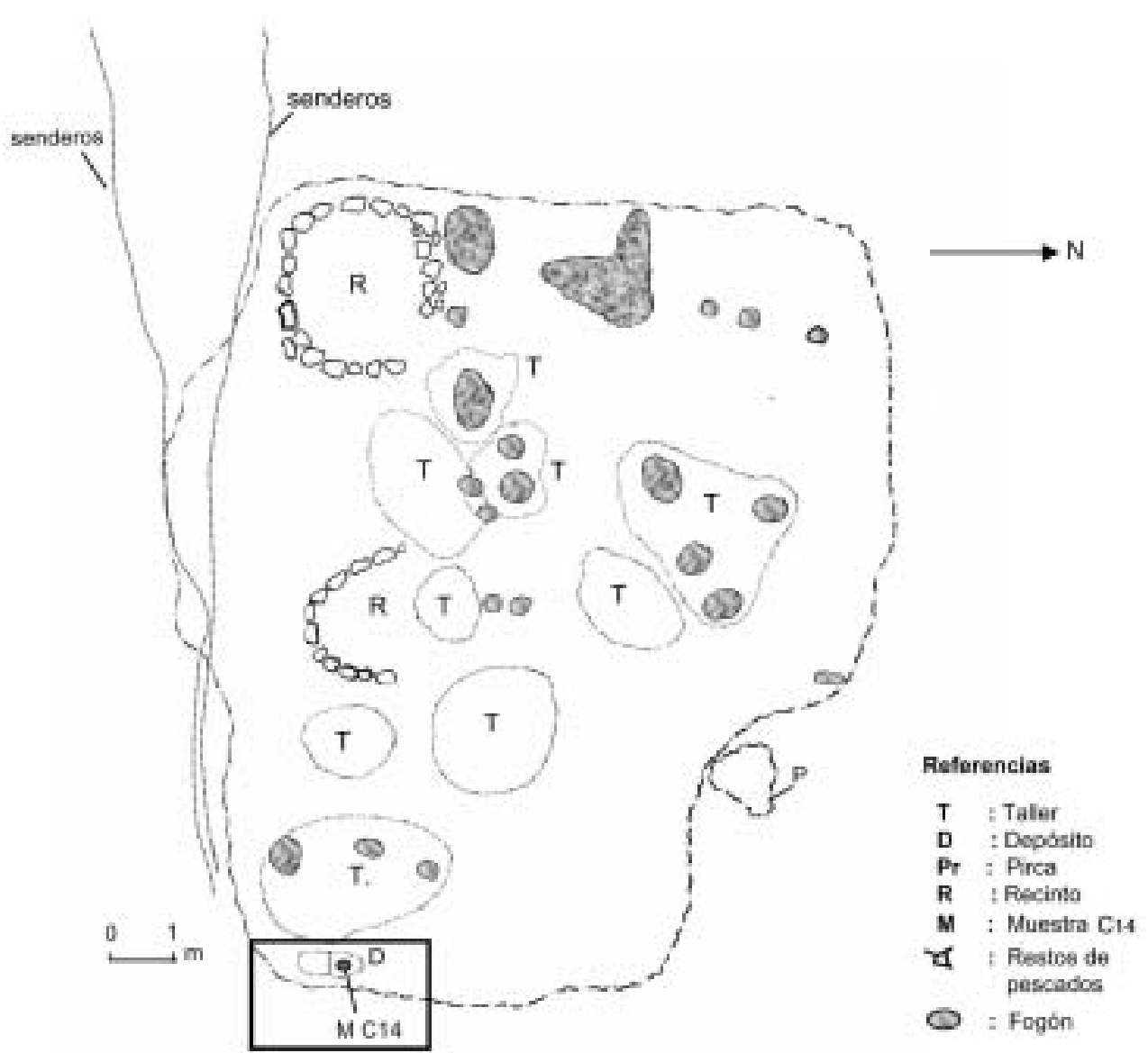

Figura 5. Cerros Pintados 3 (CP-3). Croquis de planta del campamento caravanero (paskana). Map of caravan campsite Cerros Pintados 3 (CP-3) (paskana).

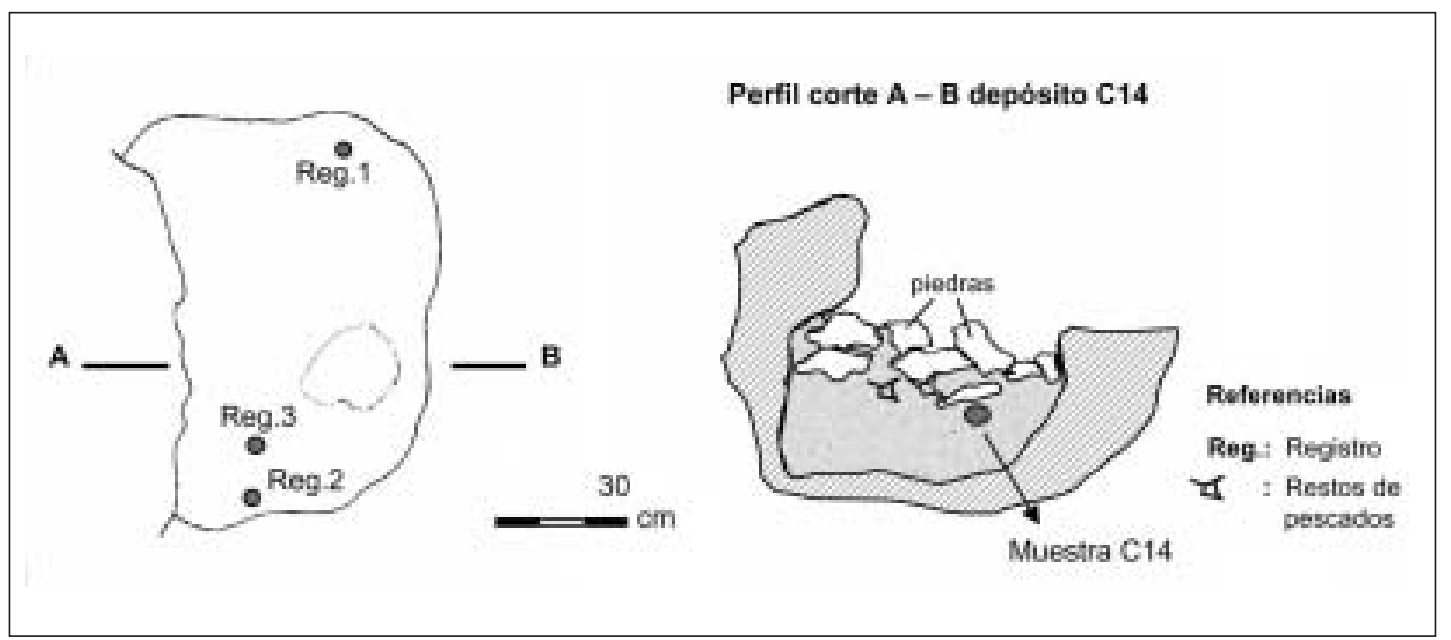

Figura 6. Detalle de planta y perfil del depósito excavado en CP-3. Detailed map and cross section of the deposit from campsite CP-3. 


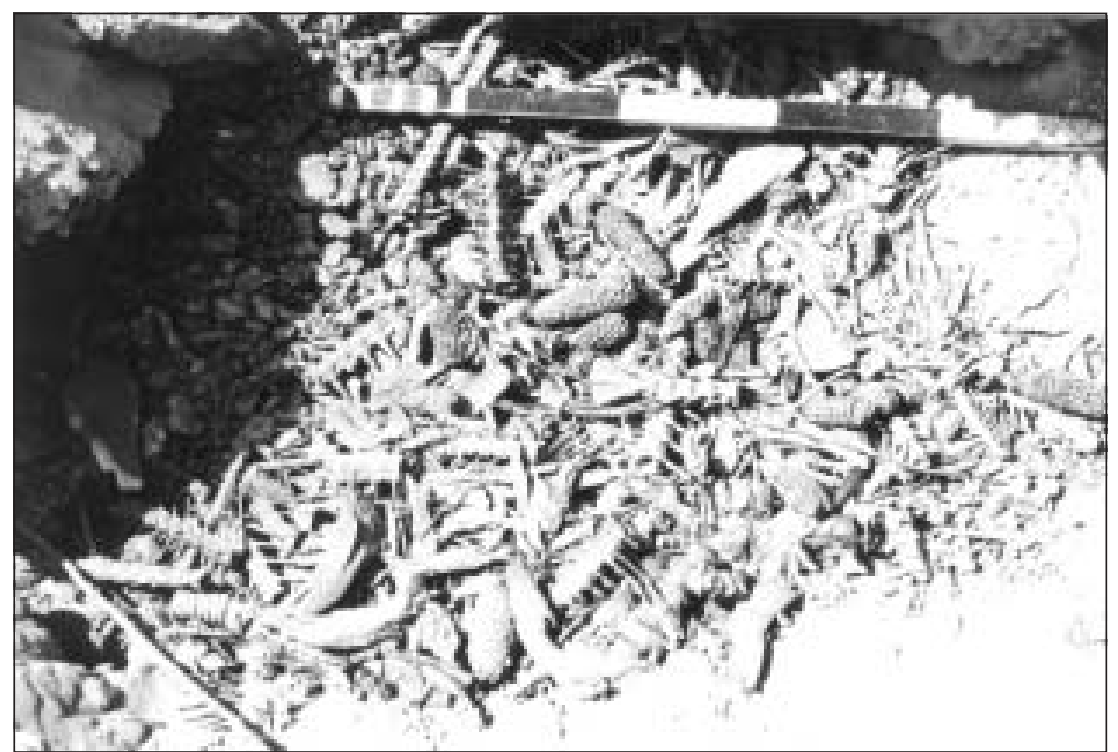

Figura 7. Depósito de restos esqueletarios de pescados y marlos de maíz del campamento CP-3. Midden deposit with fish bones and corn from campsite CP-3.

plementario: selva-altiplano-oasis-costa (Núñez y Dillehay 1979).

Cerros Pintados $1(\mathrm{CP}-1)^{5}(\mathrm{UTM} 430358 \mathrm{E}-$ $7720046 \mathrm{~N}$; 800 msm)

Del total de geoglifos en Cerros Pintados, el $50 \%$ corresponde a figuras geométricas y el $50 \%$ restante lo comparten las antropomorfas y las zoomorfas. La diversidad de figuras le da al sitio un marcado dinamismo visual con escenas de labores cotidianas, tales como la pesca, caza y caravaneo. Por otro lado, la alta frecuencia de figuras geométricas revela que el sitio concentra una lectura abstracta complementada con escenas naturalistas, representada con la fauna propia del ambiente continental y marítimo, además de personajes (reales o míticos) representados con atributos extracorporales que indicarían cierta jerarquía social o étnica.

\section{Figuras geométricas}

El "rombo" es el de mayor representatividad debido a su recurrencia, complejidad del diseño, ubicación, y presencia aislada y/o agrupada con otras figuras. Geométricamente es un polígono regular escalerado constituido por tres, cuatro, cinco y más cuadros por lado, con un segmento superior, "cabeza"; inferior, "base", y dos laterales, "brazos".
$(222.0)^{7}$ (Figura 8). Estos rasgos se interpretan como un imaginario antropomorfo, es decir, estaríamos frente a la representación hipotética de un personaje importante en el ámbito religioso, político o ideológico. Las variables de tipos y subtipos se sustentan en que no todos los "rombos" son iguales. Las diferencias pasan por: (a) el número de escalones que lo estructuran (desde 3 hasta 12); (b) las variables en "cabeza, base y brazos" como si fueran antropomorfos y que constituyen los cuatro vértices; (c) por el tamaño; (d) por el contexto en que se exponen, tanto aislados o compartiendo con otros iguales, o incluidos como parte de otros diseños. Estas diferencias pueden atribuirse a autorías, temporalidad y ritualidad, reconociendo a algunos como los prototipos iniciadores de un patrón escalonado, cuya manifestación más clásica congregaría el mayor compromiso simbólico, tanto por su estructura como por su posición estratégica asociado a senderos caravaneros.

En un análisis formal se distingue la "figura antropomorfa de cuerpo de lados cóncavos" $(105.0)^{7}$; este rasgo se repite en el cuadro superior o "cabeza" e inferior o "base" de los rombos. Esta similitud se reforzaría al reconocer cómo la figura humana se geometrizó o, viceversa, la figura geométrica se humanizó. Aunque esta relación pudiera parecer discutible, desde un análisis de diseño plástico es coherente y factible, consecuente con un patrón cultural definido. El tema queda 


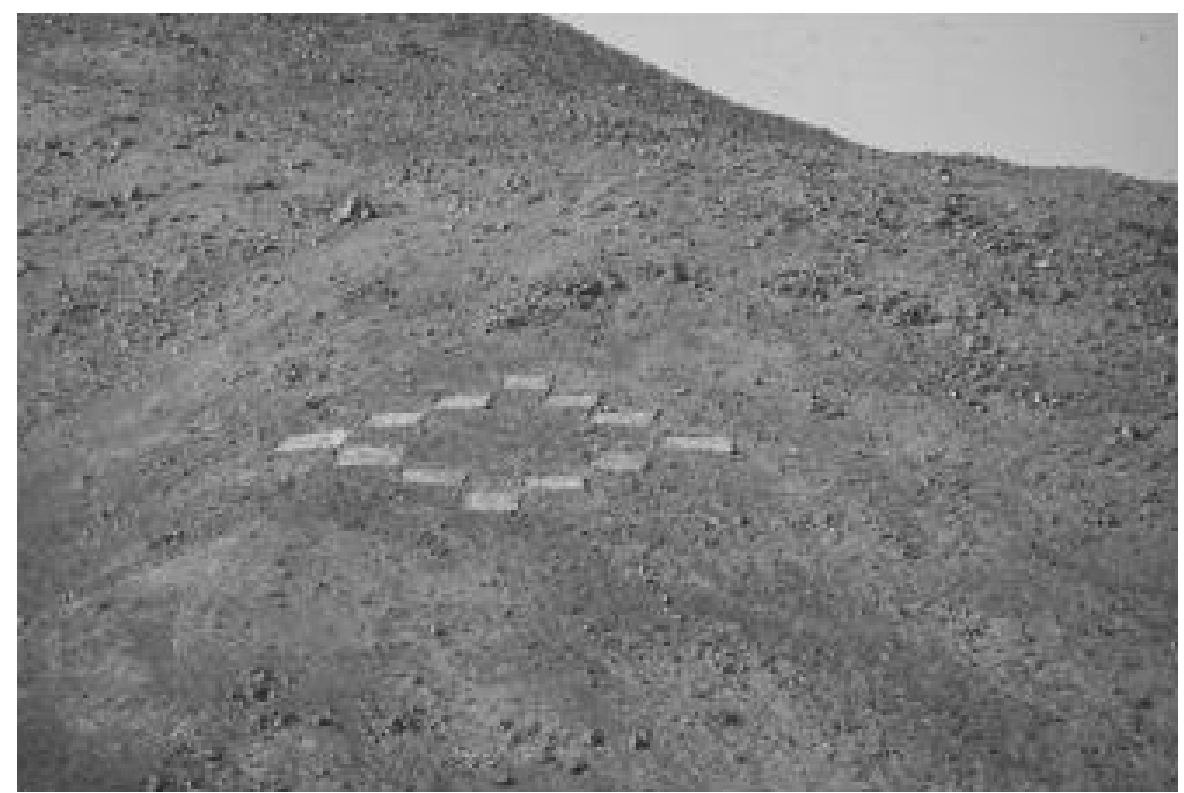

Figura 8. Geoglifo rombo escalerado, Cerros Pintados-1.

Staircased rhomboidal geoglyph, Cerros Pintados-1.

abierto a futuras aproximaciones. Lo seguro es que el "rombo", como figura geométrica emblemática, tiene una amplia dispersión en el desierto tarapaqueño. Pudo haber desempeñado un rol importante como "demarcador" de las interdigitaciones territoriales del régimen caravanero entre distintas entidades étnicas (Berenguer 1998b; Briones y Chacama 1994; Van Hoek 2004).

En CP-1, está expuesto en más de diez paneles, ocupando los sectores superiores de los cerros (Figura 8). La variable más importante es el "rombo escalonado regular y simple", de tres cuadros por lado, dejando inscrita, en negativo, una "cruz de lados iguales", generalmente asociada a otro motivo geométrico. Las variantes conocidas son "cruz simple de lados iguales" y "cruz doble de lados iguales", esta última en técnica mixta donde la "cruz" interna está en positivo y la externa en negativo.

Otros geométricos incluyen "cuadrados", "rectángulos" y "círculos." Precisamente la figura de mayor envergadura del sitio es un círculo, donde la intención fue que el geoglifo fuera visto a distancia por el caravanero que viene al encuentro de Cerros Pintados desde los oasis de Pica. Otros geométricos son similares a "grecas lineales" semejantes a las decoraciones de la textilería del Periodo del Desarrollo Regional.

\section{Figuras zoomorfas}

Representan el 25\% del total de figuras en el sitio, siendo los camélidos, aislados o constituyendo caravanas (Figura 9), los más comunes. La figura más popular se identifica como un "camélido de fisonomía rectilínea, con representación de extremidades anteriores y posteriores de perfil..." $(300)^{7}$ y como "camélido de fisonomía rectilínea, con extremidades anteriores y posteriores diferenciadas" $(301)^{7}$. Esta diferenciación tipológica es un indicador cultural y cronológico que se podría complementar con el análisis comparativo de figuras similares identificables en cestería, textilería y cerámica, asociadas a contextos con fechados absolutos. La representación de camélidos fue fundamental por su potente valor económico y simbólico al interior del pensamiento andino regional, vinculado con la crianza y uso caravanero, testimoniado a través de una intensa ritualidad por medio de ofrendas, sacrificios y su presencia aún activa en travesías de larga distancia (Gundermann 1984).

Se reconocen otras figuras zoomorfas como: zorros (caniforme), águilas (vulturiforme), especies de alta mar, como tiburón ${ }^{11}$ (Figura 10) (Oscar Varela, comunicación personal 2005), pez aguja o delfín (escualiforme) y posibles felinos (feliniforme). En contraste, no se identifican lagartos (sauriforme), 


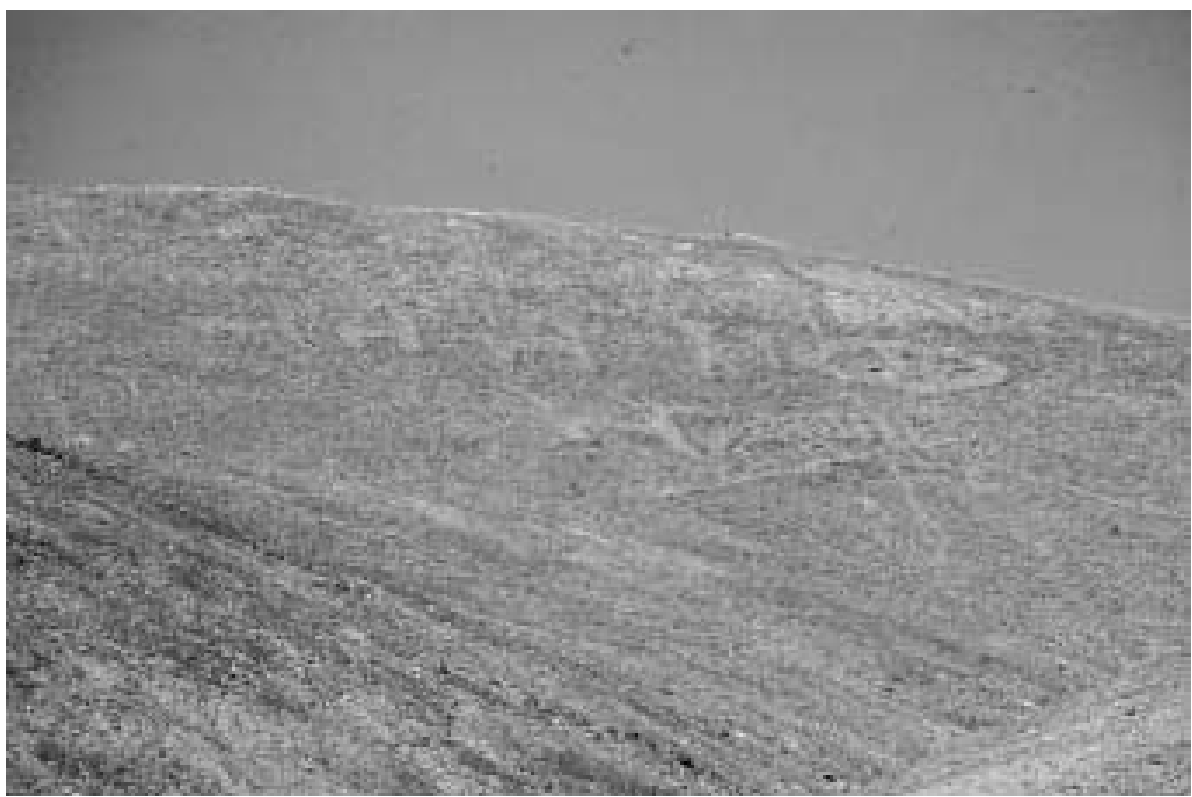

Figura 9. Geoglifo caravana de llamas, Cerros Pintados-1.

Llama caravan geoglyph, Cerros Pintados- 1 .

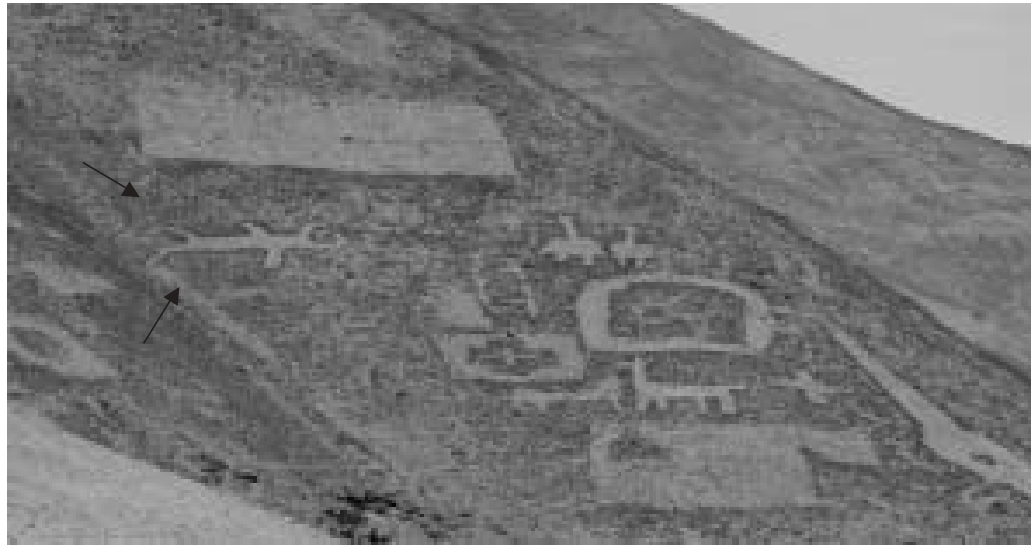

Figura 10. Geoglifo tiburón con fauces abiertas, Cerros Pintados-1. Open jaw shark geoglyph, Cerros Pintados-1.

sapos (batraciforme) y culebras (serpentiforme), lo que es un rasgo interesante de evaluar, considerando la presencia de éstos en otros sitios de la transecta en estudio. Los diseños de peces marcan la presencia de una población costera que conocía la fauna marítima en sus detalles, en especial tratándose de especies "de alta mar" (Figura 10).

\section{Figuras antropomorfas}

Los antropomorfos representan el $25 \%$ del total de geoglifos registrados en el sitio. En un nú- mero menor están los antropomorfos en actitud de movimiento, interpretados como balseros, pescadores, cazadores marítimos, guías de caravanas, personajes jerárquicos y otros (Figura 11). En este grupo se destaca una serie de antropomorfos que sustentan el estilo Cerros Pintados (Briones 1985; Santoro y Dauelsberg 1985), definido por figuras de "cabeza bifurcada en negativo, cuerpo seccionado verticalmente por el centro y de lados externos cóncavos, aparentemente sin extremidades" $(105.1)^{7}$ (Figura 12). Los subtipos conservan un denominador, sus "cuerpos de lados cóncavos". 


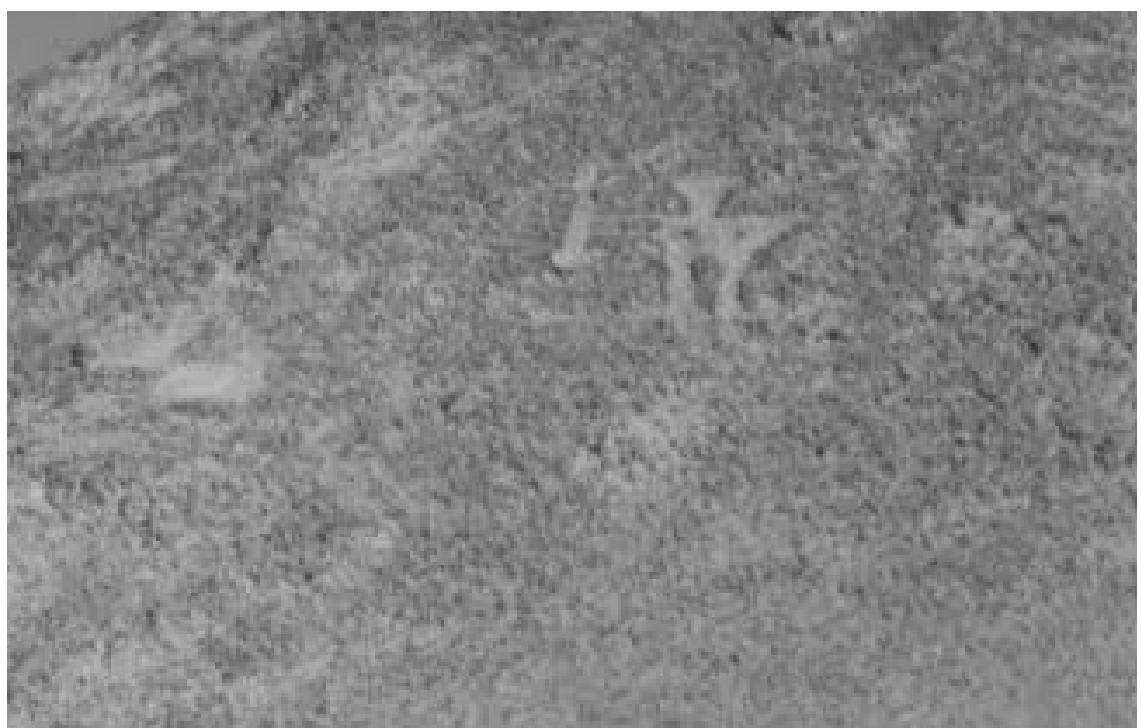

Figura 11. Geoglifo personaje en balsa con arpón, Cerros Pintados-1. Geoglyph of a person on a raft with harpoon, Cerros Pintados-1.

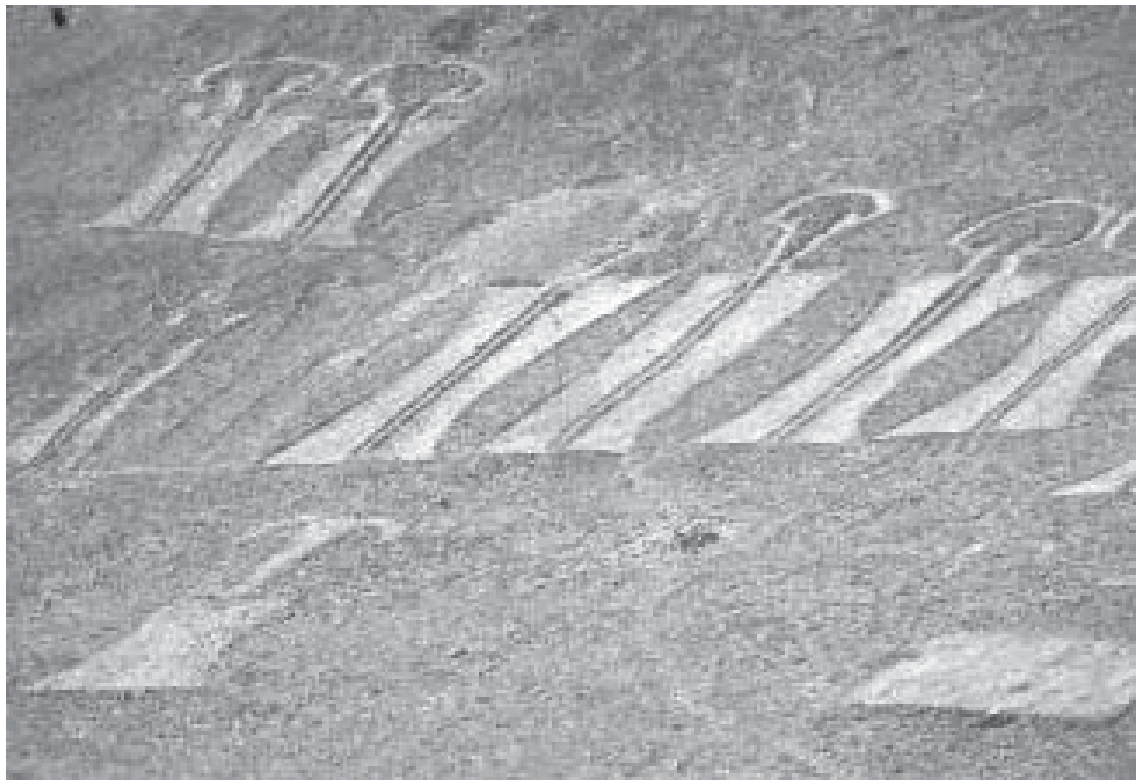

Figura 12. Geoglifos patrón antropomorfo, Cerros Pintados-1. Anthropomorphic patterned geoglyph, Cerros Pintados-1.

Algunas figuras, aunque formalmente se alejan del patrón, mantienen esta idea básica y se definen como "keriformes" y "campaniformes". Aquí al parecer, culmina el desarrollo del estilo en su aspecto formal. El patrón antropomorfo de Cerros Pintados lo sugerimos como un diseño alóctono (Briones 1985), cuya génesis habría que escudriñarla en el noroeste argentino, en técnica de grabado y pintado (Podestá y Rolandi 2001). Está pre- sente además en espacios geográficos intermedios como Atacama y Santa Bárbara, en técnica de grabado o petroglifo (Berenguer 1994, 1995, 2004).

Dos consideraciones legitimizan a CP-1 como un sitio de relevancia macrorregional: (a) tendría relación con su localización en referencia al cambio ritual del paisaje (pampa-cerro), a la serranía adecuada para la aplicación de las técnicas (cubiertas oscuras) y a recursos mínimos para la protec- 
ción y mantención del tráfico regional trasandino y transdesértico. En este sentido, fue una alternativa segura como "estación" con reservas de agua, forraje y espacio abrigado; (b) corresponde a la penetración más interior de la cordillera de la Costa, hacia la depresión intermedia, a manera de una península que se interna en la pampa. Este acercamiento estimuló el trazado de rutas entre la precordillera-oasis-costa, con menos dificultad en torno a fuentes de alimentos alternativos para sus animales, e hicieron posible organizar y abastecer esos contactos a través de despoblados absolutos (Muñoz y Briones 1998).

Desde Cerros Pintados remontan importantes senderos abriéndose hacia diversos puntos de la cordillera de la Costa. Desde este sector, se vislumbra la proximidad de un ambiente marítimo, una brisa húmeda y fresca muy diferente al ambiente salino y seco de la pampa del Tamarugal y del salar que ha quedado atrás. En el tramo Cerros Pintados-Pan de Azúcar, se localizan a lo menos tres paneles con geoglifos de "círculos", "llamas" y "rombos" de menor envergadura. Un conjunto más complejo es el que se observa en el faldeo oriental del cerro Pan de Azúcar, donde los senderos que provienen de $\mathrm{CP}-2$ o $\mathrm{CP}-3$ se bifurcan, uno hacia el oeste rumbo al salar de Soronal y el otro, con un leve rumbo oeste-sur-oeste, con destino al río Loa o costa inmediata a su desembocadura, circunvalando el salar Grande (Figura 2). El intenso trazado definido por los senderos tipo "rastrillo", es un claro indicador del rol de Cerros Pintados, por cuanto se presenta como un centro convergente entre cualquier punto de la costa aledaña con los oasis del interior.

\section{Cerro Pan de Azúcar}

El cerro Pan de Azúcar se ubica a $5 \mathrm{~km}$ al oeste de Cerros Pintados. Se identifican geoglifos (Figura 13), un campamento, una paskana y senderos menores en relación a las rutas anchas y muy marcadas del tipo "rastrillo" que cruzan frente al cerro Pan de Azúcar.

\section{Campamento Pan de Azúcar 2 (PA-2) ${ }^{5}$ (UTM $423850 \mathrm{E}-7717420 \mathrm{~N} ; 1.120 \mathrm{msm}$ )}

Corresponde a un campamento ubicado a unos $100 \mathrm{~m}$ al sureste del cerro con geoglifos. Aquí se identificó un área de pisos vinculados con el mantenimiento de llamas, en depresiones selladas por rellenos de acumulación. Se realizaron dos tests estratigráficos, los que resultaron contener restos de hojas y marlos de maíz, utilizados como forraje, probablemente trasladado desde los oasis, asociados a coprolitos de llamas.

Una paskana corresponde a una pequeña protección pircada donde se identificó un depósito con restos orgánicos. El estrato I, semiestéril con registros vegetales en sedimentos no compactos, con intervenciones subactuales, aunque el registro de coprolitos de llamas en la base del depósito podría considerarse no alterado. El estrato II presenta mayor actividad cultural (zona punteada) (Figura 14), donde se registraron fragmentos de tiestos cerámicos tardíos del complejo Pica-Tarapacá, coprolitos de llamas y vértebras de pescado. Se trataría de un área de actividades domésticas, vinculada con la preparación de alimentos, donde los coprolitos de llamas presentes allí podrían haber sido trasladados por el viento.

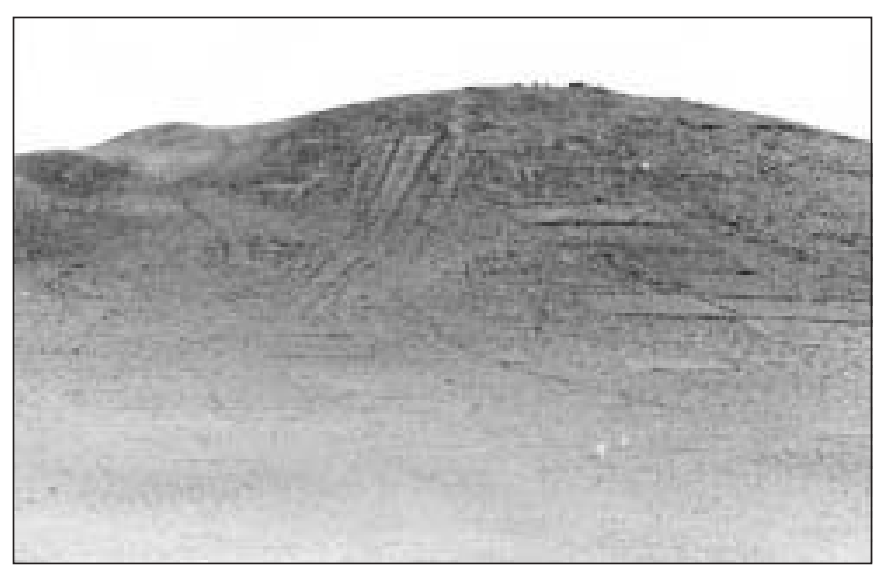

Figura 13. Geoglifos geométricos, cerro Pan de Azúcar-1.

Geometric geoglyphs, Cerro Pan de Azúcar-1. 


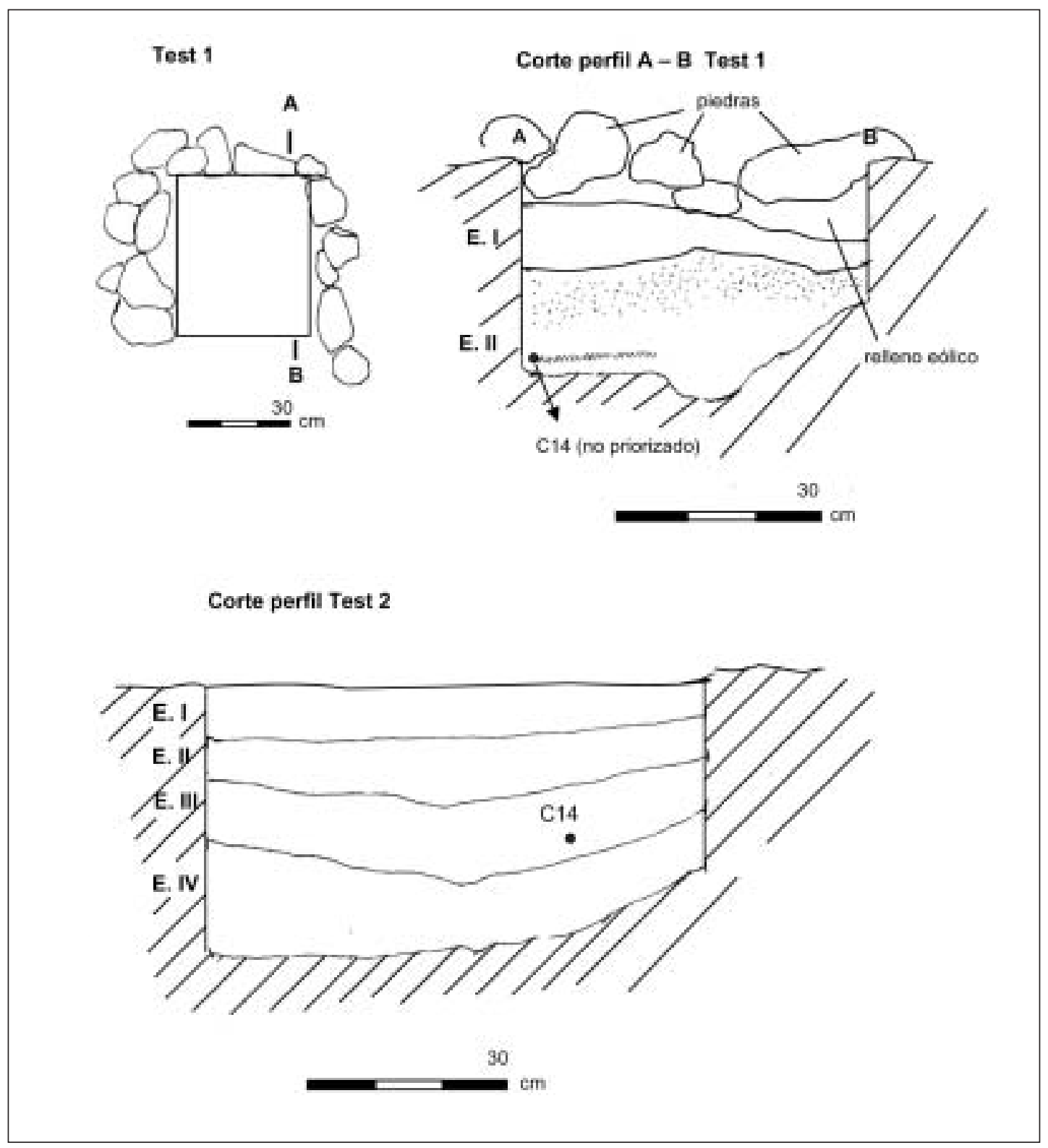

Figura 14. Planta y perfil de campamento caravanero Pan de Azúcar-2. Estratigrafía Test 1: E.I: semiestéril, sedimentación no compacta. Presencia de fibra vegetal, hojas de maíz. E.II: cultural asociado a fragmentación de cerámica, coprolitos de camélidos y restos óseos de pescados. Test 2: E.I: relleno eólico. E.II: depósito orgánico asociado a maíz y coprolitos de camélidos. Coloración ocre. E.III: escasa ocupación. Relleno de arena - anhidrita. Presencia orgánica asociada a hojas de maíz, coprolitos de camélidos y carbones. E.IV: relleno eólico semiestéril.

Bottom and side views of campsite Pan de Azúcar-2. Test 1: E.I: Loose soil with vegetable remains and corn husk. E.II: Cultural stratum with pottery, camelid coprolites and fish bone remains. Test 2: E.I: Eolic sand deposit. E.II: Organic stratum with corn and camelid coprolites remains. Ochre color. E.III: Few cultural remains in a sandy matrix. It includes corn husk, camelid coprolites and charcoal. E.IV: Eolic sandy deposit, semisterile. 
En una depresión sin estructura visible, como las observadas en los revolcaderos de camélidos o en sitios de descanso de caravanas etnográficas, se realizó el segundo test de 75 x $50 \mathrm{~cm}$, que expuso un depósito orgánico bajo la superficie estéril (relleno eólico) (Figura 14). En el perfil se observa el estrato I, compuesto por fibra vegetal muy triturada con desechos de hojas de maíz (chala), que da lugar a un sedimento de coloración amarillo asociado a coprolitos de llamas. El estrato II indicaría una menor ocupación, con relleno de arena eólica disgregada y bolones de anhidrita, de eventos de abandono. El estrato III presenta un denso depósito con hojas de maíz bien identificadas, asociadas a coprolitos de llamas y escasos restos de carbón. De este estrato proviene la muestra de coprolitos de llamas, datados en $450 \pm 40$ a.p. (Beta-150708), calibrada en 1.430 - 1.460 años d.C. (un sigma), coherente con eventos caravaneros del fin del Desarrollo Regional. El estrato IV es estéril y se corresponde con un relleno eólico sobrepuesto a la base compacta.

La presencia de hojas de maíz es la primera evidencia de forrajeo de llamas caravaneras de esta naturaleza (chala), trasladadas desde el oasis de Pica, donde su cultivo era el más dominante durante esa época.

Cerro Pan de Azúcar 1 (63.0) $)^{5}$ (UTM 424050 E $7717378 \mathrm{~N} ; 1.120 \mathrm{msm}$ )

En la ladera este del cerro Pan de Azúcar se concentran unos 55 geoglifos distribuidos en seis paneles. Un alto porcentaje incluye figuras geométricas, destacando rectas verticales y paralelas, combinadas con rectángulos y/o cuadrados de gran dimensión (Figura 13), no reconocidas en otro sitio. Las líneas rectas son elementos novedosos, debido a su gran extensión de hasta $300 \mathrm{~m}$ por $40 \mathrm{~cm}$ de ancho. Se identifican además "círculos", "rectángulos" y "rectas" que se entremezclan con las escasas figuras antropomorfas y zoomorfas.

El "rombo", que aquí tiene una representación escasa, está asociado a "rectángulos" y "cuadrados", en técnica extractiva y de gran visibilidad. Este patrón cuadrangular se identifica en Cerros Pintados, desembocadura del río Loa y salar de Soronal. En el caso del Loa, en algunos de los vértices de cada "cuadrado" se concentran pequeños montículos con restos de mineral de cobre, proveniente de las minas locales prehispánicas. La rela- ción entre arte rupestre y presencia de fragmentos de turquesa, crisocola y mineral de cobre indicaría rituales muy definidos, entre grupos de caravaneros, tanto en el Loa como Atacama y Tarapacá.

Los antropomorfos se describen como "figuras humanas de cabeza-penacho, con rectas paralelas a manera de piernas y cuerpo de lados cóncavos" $(105.1)^{7}$. Es una serie de al menos cuatro figuras humanas que se constituyen, al igual que en Cerros Pintados, en forma alineada, juntas una de otra. Un rasgo interesante es la superposición que presentan con otras figuras geométricas (cuadrados), lo que se interpreta como una reutilización del panel.

Los zoomorfos se encuentran en muy escasa representación. Se identificó un camélido de cuerpo moteado (técnica mixta), similar a los registrados en Cerros Pintados; además de una caravana de 13 llamas de "cuerpos rectos, extremidades pareadas, cuellos rectos y vestigios de cabeza, sin definirse (301.0) ${ }^{7}$.

Desde la paskana de cerro Pan de Azúcar, los senderos se internan al oeste por entre serranías y pampas, alcanzando en el tramo de una jornada (20 $\mathrm{km}$ ), el "abra" o paso obligado, conocido como cerro Mono, en clara alusión a sus geoglifos.

\section{Cerro Mono}

El distrito arqueológico de Cerro Mono se compone de: geoglifos, senderos (Figura 15), dos paskanas y dos entierros humanos ubicados en el entorno a los geoglifos. Al igual que en cerro Pan de Azúcar, no existen en cerro Mono evidencias de recursos de agua, de modo que se trata también de un paradero de corto tiempo entre los campamentos de Cerros Pintados y el salar de Soronal.

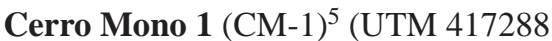

E - 7723640; $920 \mathrm{msm})$

Durante el estudio de la transecta, se identificaron en el faldeo de cerro Mono, a $50 \mathrm{~m}$ de los geoglifos, dos entierros humanos, los cuales fueron excavados con el objeto de analizar sus contextos y obtener dataciones absolutas para correlacionarlos con la paskana y los geoglifos.

Tumba 1. Bajo un emplantillado de piedras, se identificó una fosa de contorno oval, de $110 \mathrm{~cm}$ por 55 $\mathrm{cm}$ de diámetro, socavada en el piso estéril, donde 


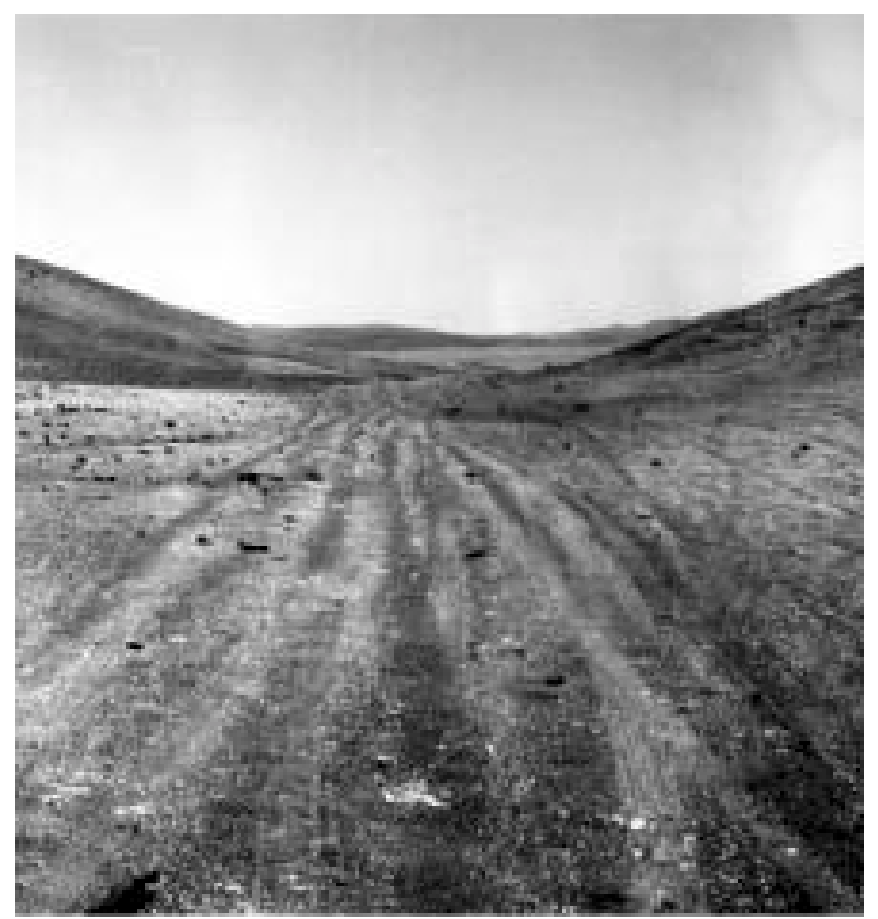

Figura 15. Rutas caravaneras asociadas a los geoglifos de Cerro Mono. Caravan routes associated with Cerro Mono geoglyphs.

fue depositado el cuerpo de una niña (10-12 años), cuyas primeras evidencias se ubican a escasos 5 $\mathrm{cm}$ desde la superficie. Se colocó decúbito dorsal extendida. El cráneo había sido removido de su posición anatómica y recolocado hacia el lado izquierdo de los pies y la extremidad superior derecha también fue removida y se ubicó hacia el lado izquierdo del tronco, a nivel pélvico. La evidencia ósea y los tejidos blandos no muestran huellas de corte que avalen la hipótesis que fue algún tipo de sacrificio ritual; tampoco hay evidencias que el desprendimiento de la cabeza y el brazo hayan sido removidos por carnívoros. Esta remoción parcial del cuerpo pareciera corresponder a un evento postdepositacional, es decir, habría sido realizado por personas que ocuparon el lugar en períodos posteriores, cuando el cuerpo presentaba ya un proceso de momificación natural y los tejidos blandos como piel y musculatura estaban secos. Su estado de conservación es parcial, con tejido muscular, piel, uñas, tegumentos faciales y cabellera.

Fardo funerario. El cuerpo de la niña fue envuelto en una piel de ave marina (con las plumas hacia fuera) y sobre ésta se observaron haces de fibra vegetal, que debieron formar parte de una estera con la que cubrieron el cuerpo.

Faldellín. Conserva restos de un faldellín in situ, a nivel pélvico. Fue elaborado en lana (café natural) y pelo, con la misma técnica constructiva de los faldellines costeros del arcaico tardío (Standen 2003), los pabilos que cuelgan tienen un largo aproximado de $20 \mathrm{~cm}$ y son cuerdas de $4 \mathrm{~mm}$ de diámetro, con torsión "s".

Sandalias. Se registraron dos sandalias confeccionadas en cuero de lobo marino. Una es de planta rectangular, $145 \mathrm{~mm}$ de largo por $55 \mathrm{~mm}$ de ancho, en cada uno de los cuatro ángulos tiene un ojal doble, por donde pasa una cuerda, también de cuero. La otra, difiere en el diseño y tamaño de la anterior, ya que tiene sólo dos ojales laterales en la parte media de la planta, por donde pasó una cuerda, también de cuero. La planta mide $125 \mathrm{~mm}$ de largo por $50 \mathrm{~mm}$ de ancho. Por las dimensiones, ambas sandalias debieron ser usadas por niños.

Peinado. Conserva restos de un peinado similar, aunque menos elaborado del que usan las pobla- 
ciones costeras Quiani, del arcaico tardío y formativo temprano en la costa de Arica (Arriaza et al. 1986; Soto 1987). La niña fue peinada con una partidura en la línea media, donde luego el cabello fue agrupado en dos moños laterales, formando los típicos “jopos”. En este caso sólo se conservó el izquierdo; corresponde a un moño (con el cabello no trenzado) de $70 \mathrm{~mm}$ de largo y $30 \mathrm{~mm}$ de diámetro, embarrilado con cuerda de lana $(1 \mathrm{~mm}$ de diámetro, dos cabos, torsión "s", asociada a una cuerda de pelo humano), cubriendo casi la totalidad del "jopo".

Otros rasgos culturales asociados a la tumba corresponden a: fragmento de cestería coiled, restos de fibra vegetal en proceso de elaboración para esteras, un fragmento de cordelería vegetal $(8 \mathrm{~mm}$ diámetro, dos haces, con torsión "z"), que conserva un nudo simple.

\section{Características Físicas del Cuerpo}

Deformación craneana intencional. Presenta una deformación del cráneo del patrón circular oblicuo, de grado moderado. Este tipo de deformación es típico del arcaico costero tardío de Arica (Munizaga 1980; Soto 1987).

Condiciones de salud. A nivel del esqueleto no se observan alteraciones que indiquen problemas de salud o procesos patológicos. Sin embargo, los tegumentos faciales que conserva sobre los huesos de la cara muestran una protuberancia de la piel, sobre el párpado del ojo izquierdo, de unos 20 x 10 $\mathrm{mm}$, que podría corresponder algún tipo de herida de origen traumático.

La salud bucal es excelente, hay ausencia de procesos infecciosos como caries o fístulas a nivel alveolar. Tampoco hay pérdida de piezas dentarias ante-morten, sólo los incisivos están ausentes por causas post-mortem. La abrasión dentaria es mínima, sólo se observa un leve desgaste del esmalte, aunque se debe considerar que corresponde a una niña, donde en general suelen presentar poco compromiso de desgaste dentario, debido a la corta edad. El patrón dentario en general es típico de las poblaciones costeras, con ausencia de caries debido a un menor consumo de hidratos de carbono, responsables directos de la alta incidencia de procesos cariógenos en las poblaciones hortícolas.
La presencia de la fosa, más el emplantillado superficial, indicarían que, si la niña falleció en la travesía entre la costa y los oasis interiores, el cuerpo no fue "abandonado" y se le preparó un ritual funerario. La posición del cuerpo, fardo, faldellín, peinado, el tipo de deformación del cráneo y el patrón dentario avalarían su procedencia costera:

Tumba 3. En este caso no se observa el emplantillado de piedras; corresponde sólo a una fosa de 80 x $50 \mathrm{~cm}$ de diámetro, donde a escasos $10 \mathrm{~cm}$ de profundidad aparece el cuerpo de una mujer (2530 años) en posición flectada decúbito lateral derecho (Figura 16), con la cabeza orientada hacia el faldeo del cerro. La tumba fue abierta durante algún momento, ya que los huesos tienen un color blanquecino, lo que indica que estuvieron expuestos. El cráneo y la extremidad inferior derecha fueron removidos; del cráneo sólo conservó parte del hueso occipital, temporal izquierdo, fragmento de maxilar y la mandíbula.

Fardo funerario. La mujer fue envuelta con una piel de ave marina, con las plumas hacia afuera. Una bolsa tipo malla elaborada en fibra vegetal (3 mm de diámetro, 2 cabos y torsión en "s") y un cesto en técnica coiled cubrían los restos óseos del cráneo.

Ofrendas. Sobre el cuerpo y al interior de la fosa se ubicaron los siguientes objetos: (a) cesto (técnica coiled) de paredes verticales y decorado con rombos, diseño que tiene directa relación con los geoglifos; (b) ceramio pequeño sin decoración (al interior del cesto); (c) alfiler de espina vegetal y restos vegetales (al interior del cesto); (d) bolsita de tejido orgánico (posiblemente intestino), embarrilada a modo de sello con una cuerda fina de fibra vegetal; (e) fragmento de tela gruesa de trama y urdimbre expuesta, en un borde tiene una decoración con lana negra y afelpada, a base de líneas verticales alternadas: una café claro y otra negra; (f) cinco fragmentos de cerámica monocroma café, sin engobe y alta incrustación de mica blanca; tres de éstos tienen perforaciones circulares que varían entre 4 a $8 \mathrm{~mm}$ de diámetro, un fragmento tiene tres perforaciones contiguas en el borde (técnica de reparación); (g) cuerda de tendón de $1 \mathrm{~mm}$ diámetro y torsión " $\mathrm{z}$ "; y (h) 10 semillas de algarrobo, eventualmente colectadas en la pampa de Tamarugal. 


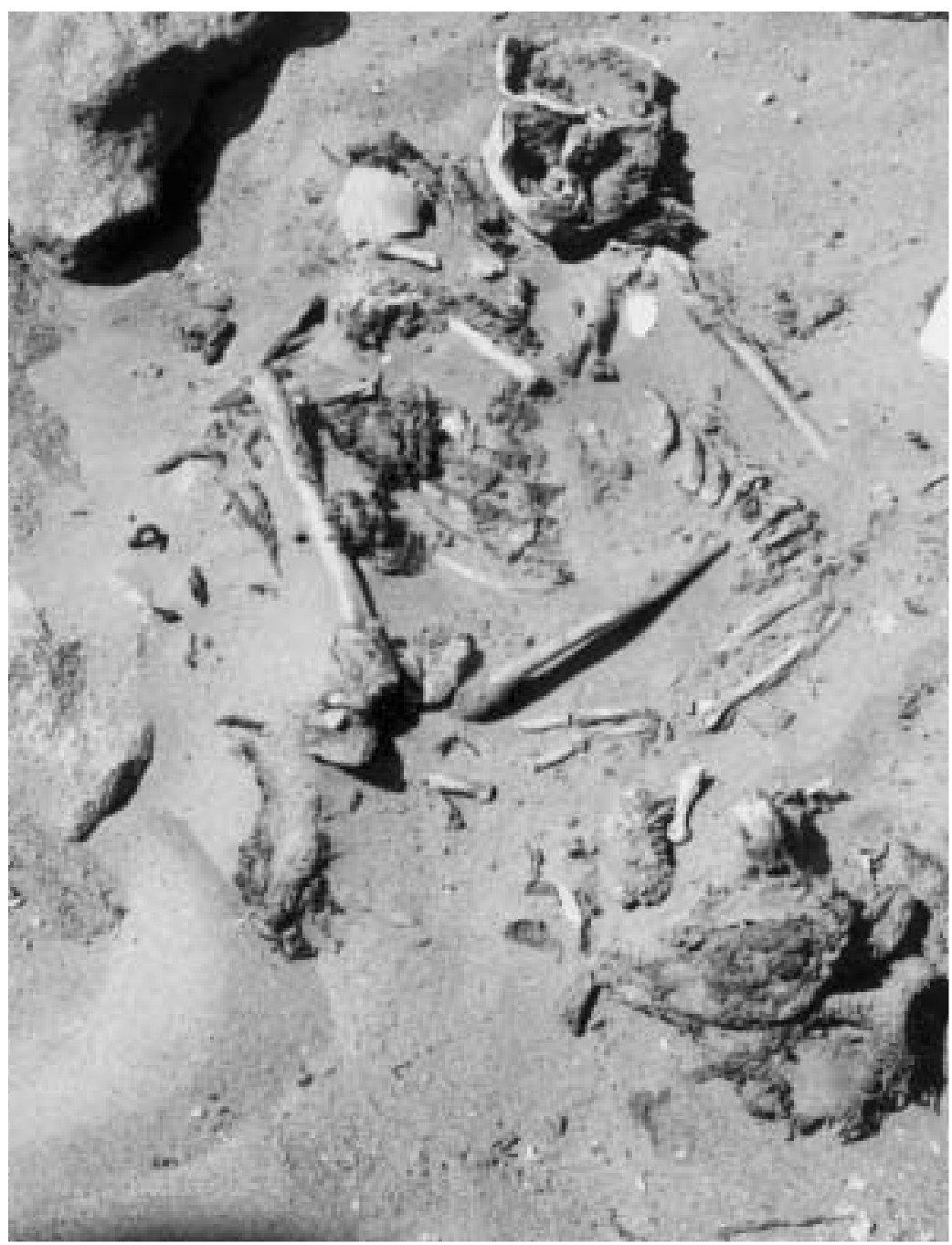

Figura 16. Contexto funerario (T-3) de Cerro Mono-1.

Funerary context (T-3) at Cerro Mono-1.

\section{Características Físicas del Cuerpo}

Deformación craneana intencional. No se pudo determinar su presencia o ausencia ya que se conservó solo parte del occipital y temporal izquierdo, muy erosionados.

Condiciones de salud. Se observó una incipiente espondilosis en la $5^{\text {a }}$ vértebra cervical (borde superior) y en la articulación sacro-lumbar (más acentuada en borde superior); estas alteraciones óseas pueden tener directa relación con el estrés corporal que generaba el traslado de cargas en capacho de productos costeros para el intercambio. Otra alteración anatómica identificada corresponde a una exostosis auditiva externa, muy incipiente y de contorno difuso, ubicado en la pared posterior del conducto auditivo de temporal izquierdo. Este rasgo anatómico es típico de las poblaciones costeras (Standen et al. 1997).

Con relación a la patología dental, la mandíbula presenta pérdida durante la vida, de los premolares y molares, donde los alvéolos están completamente reabsorbidos, lo que refleja una mala salud bucal, debido probablemente a que consumía alimentos ricos en carbohidratos y glucosa, tal como el maíz y las vainas de algarrobo. La pieza dentaria que se conserva in situ, tiene un grado de abrasión moderado, tipo plano, con escasa exposición de dentina. 
Estatura. Se calculó una estatura aproximada de $155 \mathrm{~cm} \pm 4.25$ (cálculo estimado en base al húmero) (Genovés 1961).

\section{Datación absoluta de la Tumba 1}

La tumba 1 fue datada en $3 \cdot 110 \pm 40$ a.p. (Beta50707) (músculo humano) calibrada en 3.370 3.320 a.p. (un sigma) equivalente a 1.420-1.380 años a.C. Aunque esta fecha es más temprana que los sitios antes referidos, se asume que es correcta y coherente con las características físicas y el contexto cultural asociado. Al respecto, se presentan dos alternativas explicativas: (a) si el cuerpo humano datado fue contemporáneo con los geoglifos de cerro Mono, estos son más antiguos de lo esperado, y (b) cuando el cuerpo fue enterrado en ese lugar, aún no existían los geoglifos. De ser así, esta evidencia se relaciona con desplazamientos de familias de cazadores, pescadores y recolectores costeros. En consecuencia, el ascenso hacia las pampas y oasis interiores con el objeto de explotar recursos complementarios era ya practicado por comunidades costeras. Por lo anterior, el surgimiento y uso prístino de rutas trandesérticas sería contemporáneo con la interfase arcaico tardío-formativo temprano, las cuales se habrían perfeccionado y ritualizado durante las etapas posteriores.
La mujer de la tumba 3, también es claramente de procedencia costera, aunque de data más tardía, tal como lo sugiere el patrón de pérdida de piezas dentarias, lo que indica que estaba en contacto con grupos humanos que ya practicaban la horticultura, además del contexto cultural asociado.

\section{Cerro Mono $2(35.0)^{5}($ UTM 407235 E - 7720666 $\mathrm{N}$; $930 \mathrm{msm}$ )}

Los geoglifos de cerro Mono se distribuyen en las lomas que forman la serranía de cerro Miere; en su mayoría se orientan hacia el norte, por donde pasan los senderos. Se contabilizan 137 geoglifos de proporciones y representaciones diversas, con algunos diseños exclusivos.

Los geométricos representan el 55\%, manteniendo la media que se repite en los sitios ya analizados. Los "rombos" son dominantes (17 en total) y se exponen en la sección superior y media del talud. Un "rombo" aislado marca el ingreso para el caravanero que viene desde Cerros Pintados y Pan de Azúcar; otros se orientan al norte y al oeste, marcando el ingreso y/o salida del abra de cerro Mono desde la costa (Figura 17). Los "círculos" (12 en total) con tamaños que no pasan como promedio los $2 \mathrm{~m}$ de diámetro, a excepción de una figura que mide $12 \mathrm{~m}$ de diámetro, orientada al norte. Otro panel, visible desde el oeste, muestra

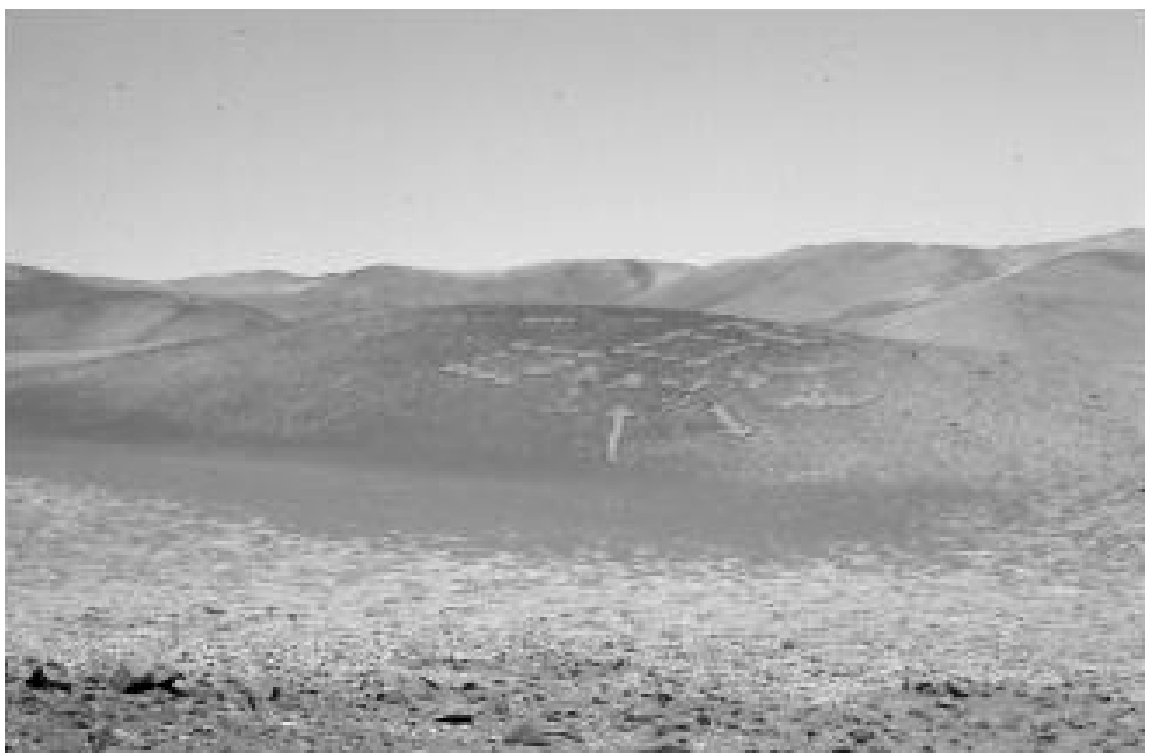

Figura 17. Geoglifos geométricos, Cerro Mono-2. Geometric geoglyphs, Cerro Mono-2. 
cuatro círculos relacionados a figuras en forma de "flechas", de 35 y 40 m de longitud (Figura 17). Independientemente del mensaje simbólico implícito en estos geoglifos, están "marcando" la existencia del abra, en especial para los que acceden, desde la costa, al sector de cerro Mono.

Otros geométricos son la "cruz de lados iguales", y variantes como una "cruz doble de lados iguales", en técnica mixta, donde la cruz interior resalta del diseño exterior por efecto de contraste, dado por la extracción y adición de material superficial (Briones 1984). Este es un geoglifo dominante en el panel, de gran dimensión, orientado al este.

Los antropomorfos representan el $21.1 \%$ del total de geoglifos, muestran rasgos comunes que definen ciertos patrones. Se describen como "antropomorfas acéfalas, cuerpo seccionado verticalmente por el centro, de lados externos cóncavos..." $(105.0)^{7}$, "antropomorfas apareadas, en actitud dinámica, de cabezas iguales, brazos alzados, cuerpos semiinclinados hacia adelante, figura posterior con representación de órgano sexual masculino, piernas semiflextadas..." $(185.3)^{7}$. Este diseño se identifica además en Alto Tarapacá, Mapocho, Alto Ariquilda Norte y salar de Soronal, estableciéndose una directa analogía con los petroglifos de Tarapacá 47 (Núñez y Briones 1967). Estamos en presencia de un patrón excepcional en el arte rupestre regional, en donde se jerarquiza el rito sexual, como una relación cúltica vinculado a la noción andina de cerro sagrado protector y multiplicador de la vida. Otros antropomorfos se repiten más al norte en Cuya, Chiza-Suca, Suca y Huarasiña, Alto Ariquilda Norte y Yungay Bajo.

Los zoomorfos constituyen el $21.8 \%$ del total de figuras, siendo los camélidos los más frecuentes, en especial, cuando se reconocen como segmentos de caravanas o aislados. Aparece por primera vez en cerro Mono la figura del "lagarto", como un nuevo diseño no registrado en los otros sitios de la transecta prospectada. Uno de ellos cubre una superficie de $200 \mathrm{~m}^{2}$ y se describe como "cabeza triangular, cuello grueso, extremidades delanteras hacia arriba en ángulo, con tres dedos, cuerpo frontal de lados curvos con manchas irregulares, extremidades traseras en ángulo hacia abajo, con tres dedos y remate de cola larga y delgada" (333.6) $)^{7}$. La figura "lagarto" se distribuye en un vasto territorio entre Camarones por el norte y el río Loa por el sur (Figura 1), mostrando una amplia variedad en su diseño (cuerpo moteado con puntos, formados de pequeños montículos de piedras o en versión no moteados, posición de las extremidades, con o sin cola), entre otras. Al igual que los "rombos", la figura "lagarto" articula ciertas rutas que unen los valles con la costa, se dispone en sectores prominentes, se elaboran de grandes tamaños, en posición de planta y verticales. Se ubican aislados y/o acompañados por "rombos", "cruces" u otros geométricos.

Se identifican además diseños aislados de aves marítimas y peces de "alta mar", al igual que en Cerros Pintados. La evidencia más clara se describe como "figura de pájaro de cabeza y pico, cuello largo ligeramente curvo, cuerpo de perfil con cola larga, dos patas largas" $(352.0)^{7}$. Otras figuras marcan la presencia de especies de la costa, distante a $30 \mathrm{~km}$ de este punto, tal como la "figura de pez, de gran tamaño, con cabeza y al parecer agallas, cuerpo alargado y aleta dorsal" (312.1) $)^{7}$, asociada a un "rombo". La figura "pez" permanece a lo largo de la ruta, en el salar del Soronal, en varios sitios de la cordillera de la Costa, y al interior como Alto Pachica y Alto Maní Norte e incluso en pleno piemonte, como en la quebrada Los Tambos, lo que da cuenta de la incorporación de iconos marítimos estimulados por la articulación ideológica con los ambientes del Pacífico.

\section{Salar de Soronal}

La cuenca del salar de Soronal se ubica a unos $10 \mathrm{~km}$ al oeste de cerro Mono, en plena cordillera de la Costa, se caracteriza por una depresión rodeada de cerros bajos por el este y altos por el oeste (cerro Soronal $1.000 \mathrm{msm}$ ). En el sector sur, la presencia de una aguada le otorga al paisaje un aspecto exótico, con una vegetación estable de sorona (Tessaria absinthioides) y grama salada (Distichlis sp.).

Aquí, se han identificado: geoglifos, rutas y senderos, cementerios y extensos campamentos con abundantes depósitos antrópicos que alcanzan los $5.000 \mathrm{~m}^{2}$ (Núñez y Varela 1961). Estos registros dan cuenta de la importancia que mantuvo este lugar como vínculo clave en la logística del tráfico entre los oasis del interior y la costa, esta vez separado solo por una jornada equivalente a $20 \mathrm{~km}$. Los senderos que ingresan al salar lo hacen por el sureste (sector de la aguada), nordeste (sector cementerio cristiano) y norte (costado de cerro Ca- 
mello). Los senderos de salida, para conectar con la costa, lo hacen por el suroeste.

Campamento Soronal 3 (S-3) $)^{5}$ (UTM 398415 E - $7722257 \mathrm{~N}$; $748 \mathrm{msm}$ )

Al pie del principal cerro con geoglifos, se han identificado extensos campamentos y cementerios prehispánicos de diversas épocas, en torno a recursos líticos, hídricos y vegetacionales (Núñez 1963, 1966). Para establecer una posible relación entre rutas, geoglifos y asentamiento, se examinó un campamento con depósitos estratificados (S-3). Se procedió a despejar un perfil anterior y se excavó un test de 60 x $40 \mathrm{~cm}$ a través de un corte cronoestratigráfico que alcanzó una profundidad de 220 $\mathrm{cm}$, con depósitos superpuestos separados por leves sellos de arena eólica correspondientes a abandonos de corta duración (Figura 18). Desde el comienzo de ocupación se registraron abundantes evidencias orgánicas: maíces, restos vegetales, plumas y huesos de aves y peces marítimos. Se obtuvo una muestra de carbón del nivel medio del perfil estratigráfico, E-XIII (Figura 18), arrojando una datación de $1.450 \pm 40$ a.p. (Beta-150711), calibrada en 1.360 - 1.300 años a.p. (un sigma) equivalente a 650-980 años d.C.

Dada la disponibilidad de los recursos, incluyendo la cercanía del litoral y el acceso a los bosques del Tamarugal, esta cuenca fue un punto de contacto importante actuando como puerto de tráfico e intercambio entre los pescadores del litoral y los caravaneros del interior (Núñez 1985a), estableciéndose probablemente como un espacio de uso multiétnico, hipótesis que podría avalarse con futuras excavaciones.

De acuerdo a la datación del depósito, sería probable que desde los 650 d.C. e incluso antes (ya que la muestra no proviene de los inicios de ocupación del montículo, además de la datación de cerro Mono) estas rutas ya estaban en funcionamiento. Estas evidencias sugieren que: (a) la intensidad de la ocupación examinada se podría correlacionar en principio con la alta densidad de geoglifos; (b) en el tiempo fechado, los geoglifos o recién se inician, o ya eran populares, asociados a un activo tráfico interregional oasis-costa de data formativa o anterior; y (c) en el rango entre 650980 años d.C. las ocupaciones que constituyen los montículos de basura, practican operaciones y rituales de tráfico, al pie de los geoglifos del Soronal.
En consecuencia, esta datación obliga a establecer secuencias de estilos, con algunos componentes de data cronológica más temprana, sin descartar otros formativos ya mencionados.

En suma, estas dataciones son las primeras aproximaciones para la problemática cronológica de campamentos y cementerios vinculados con geoglifos, y abren importantes expectativas para lograr más dataciones en torno a las interacciones viales y la consecuente identificación de componentes directos del tráfico (p. ej., coprolitos de llamas). De hecho, en Soronal se han excavado entierros humanos en la cúspide de estos montículos con contextos caravaneros muy específicos provenientes de los oasis (Núñez 1985a). El hallazgo de un portacarga escalerado de madera es similar a uno excavado en el cementerio Pica 7, asociado a anzuelos de cobre y balsa de tres palos, con tiestos cerámicos del estilo Saxamar (inca altiplánico) (Núñez 1962). Con estas evidencias se introduce otro factor temporal, esta vez algo más tardío de las consideraciones cronológicas anteriormente comentadas, proyectando el uso de estas rutas hasta el contacto inca altiplánico (Núñez 1963, 1985a).

\section{Geoglifos de Soronal}

Sector Aguada $(5.0)^{5}($ UTM 98500 E - 7721344 $\mathrm{N} ; 750 \mathrm{msm}$ )

Los geoglifos se localizan en el faldeo oeste del cerro San Luis, en el borde sureste del salar (S-2, según Núñez y Varela 1961-4). De un centenar de figuras, 56 son zoomorfas, 21 antropomorfas y 19 geométricas. Presentan situaciones de superposición, donde el trazado más temprano corresponde a geoglifos con técnica extractiva o raspado y son de mayor tamaño, especialmente los "rombos" asociados a "figuras humanas" del patrón Cerros Pintados, y tienden a ubicarse en la sección superior del cerro (Figura 19). Los diseños más tardíos son de dimensiones menores y con técnica aditiva, donde predominan "camélidos" y "fauna de ambiente marítimo" con algunos "rombos" (Briones 1984), y tienden a ubicarse en la medianía y base del cerro (Figura 20). En norte de Chile, no existe otro sitio similar donde con tanta claridad se manifieste la superposición de patrones diferentes, aspecto que se correlaciona con el amplio rango temporal registrado en las ocupaciones estratificadas identificadas en el montículo datado. 


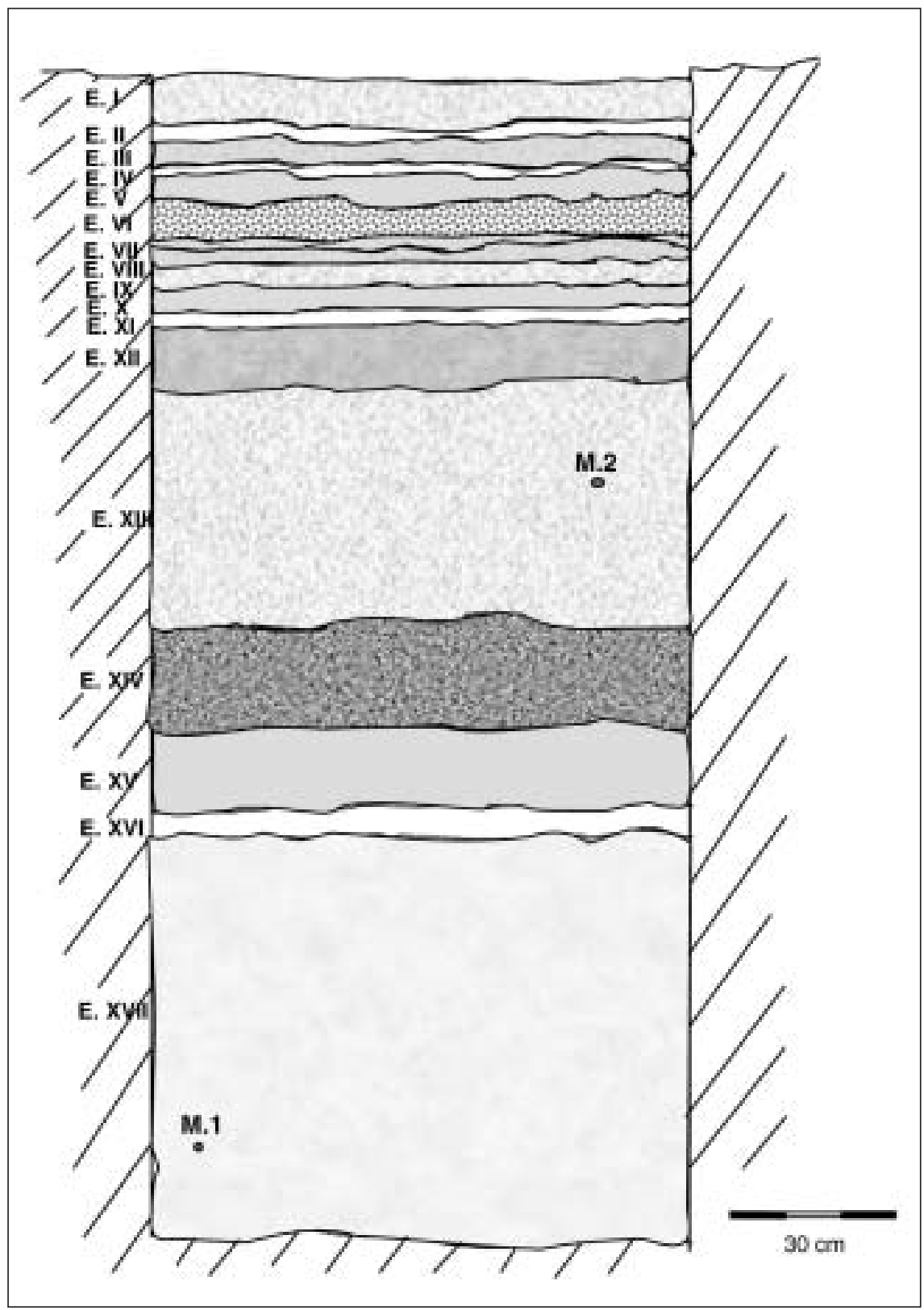

Figura 18. Corte estratigráfico en el campamento monticulado de Soronal-3. E.I: ceniza, vegetales y vértebras de pescado, E.II: estéril, E.III: restos de pescado y aves, E.IV: microestrato estéril, E.V: arena eólica, E.VI: orgánico, E.VII: arena semicompacta, E.VIII: arena, residuos, plumas y huesos, E.IX: arena, cenizas y plumas, E.X: arena fértil, E.XI: arena estéril, E.XII: depósito semifértil, E.XIII: depósito fértil, maíces, carbones. (Muestra 2, carbones $\mathrm{C}^{14}$ ), E.XIV: depósito estéril, paja y plumas, E.XV: depósito fértil, E.XVI: estéril, E:XVII: depósito semiestéril. Material fino (Muestra $1 \mathrm{C}^{14}$ ).

Stratigraphic cut at Soronal-3 mound campsite. E.I: Ashes, vegetal and fish bone remains; E.II: Sterile; E.III: Fish and bird bones remains; E.IV: Sterile micro-stratum; E.V: Eolic sand; E.VI: Organic stratum; E.VII: Semi-compact sandy stratum; E.VIII: Feathers, bones remains and sand; E.IX: Ashes, feathers and sand; E.X: Fertile cultural deposit and sand; E.XI: Sterile sand; E.XII: Semi-sterile deposit; E.XIII: Fertile deposit, corn, charcoal (Sample 2, radiocarbon); E.XIV: Sterile deposit, straw and feathers; E.XV: Fertile deposit; E.XVI: Sterile; E.XVII: Semi-sterile deposit. Fine grain sediment (sample 1 radiocarbon). 


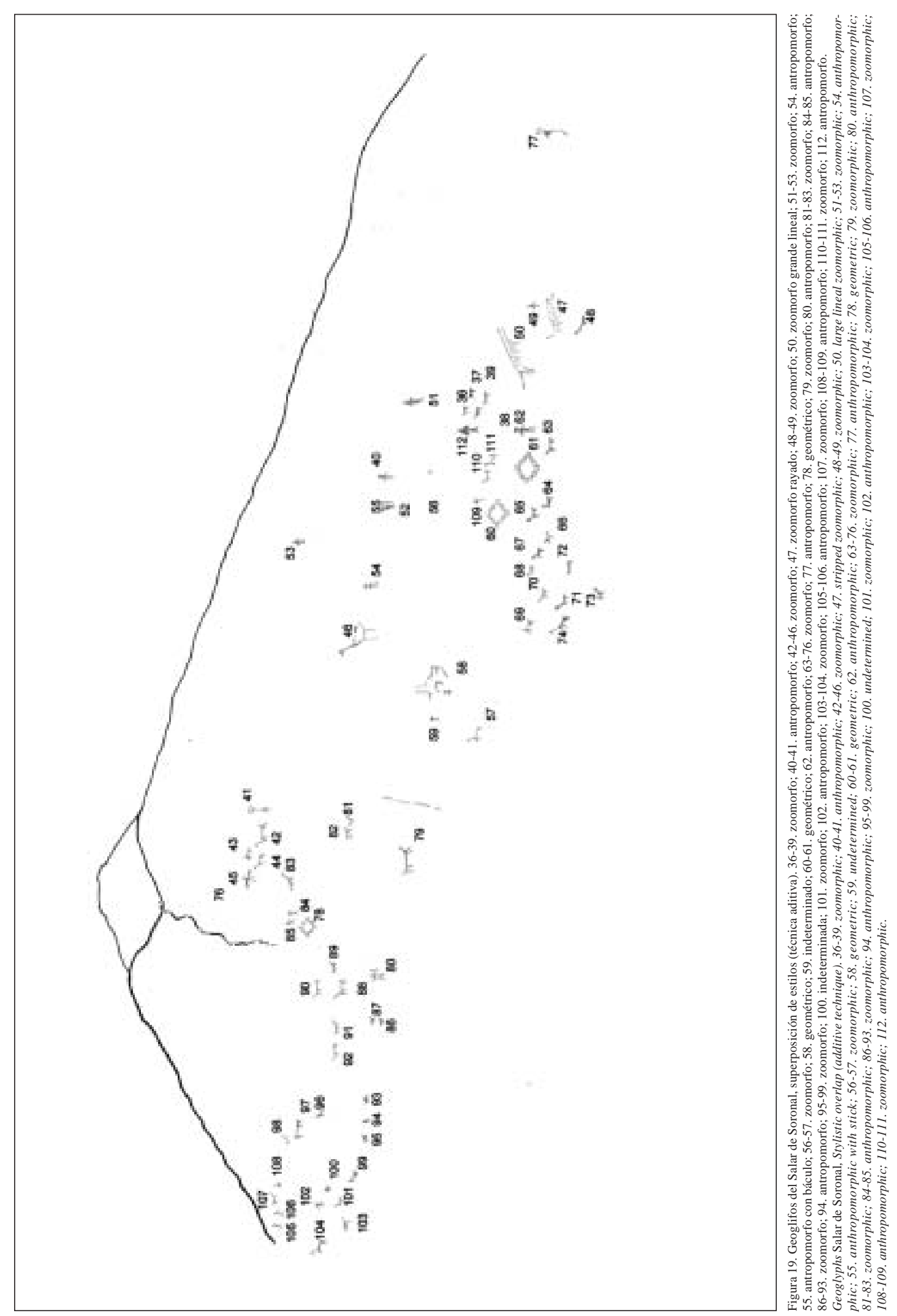




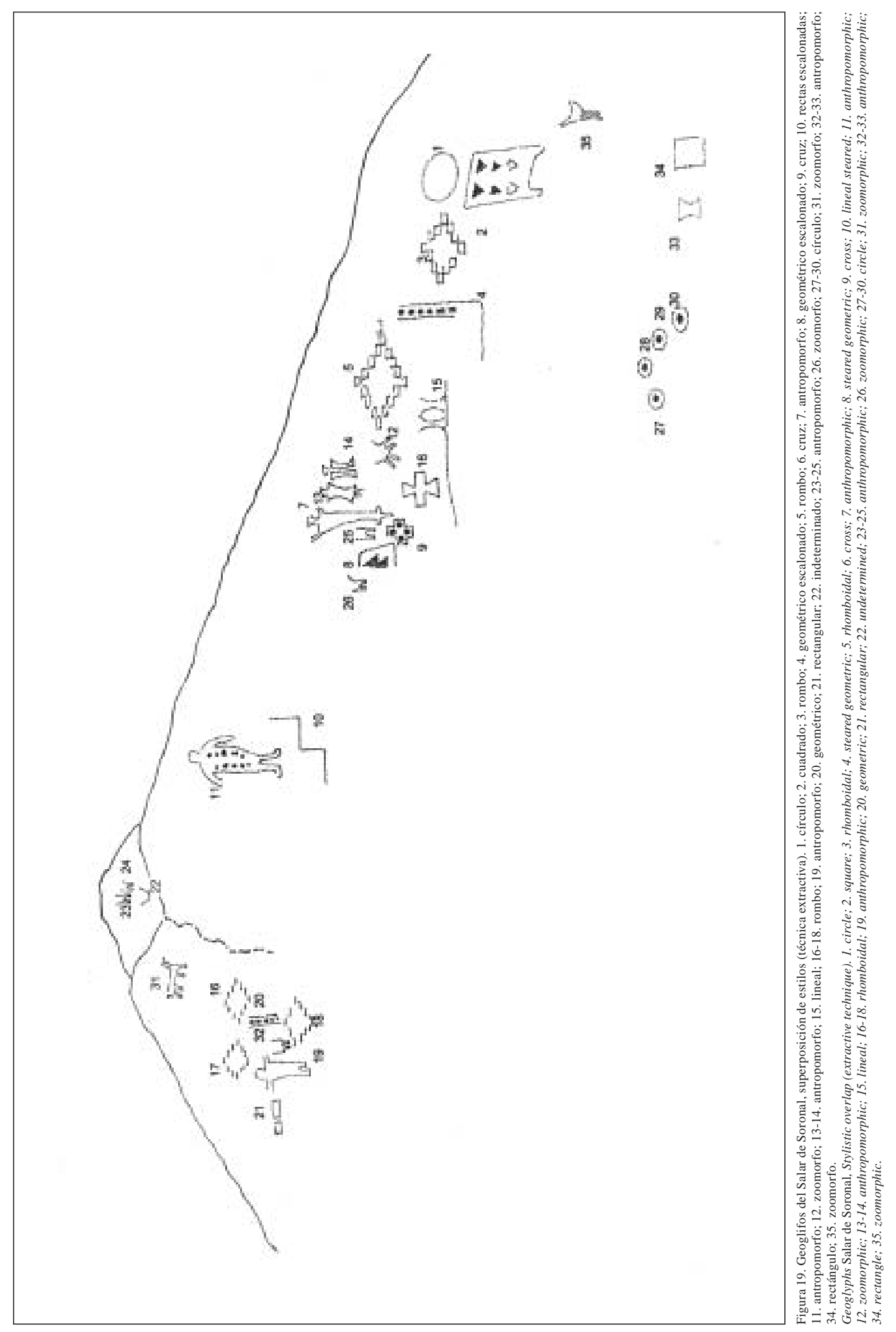




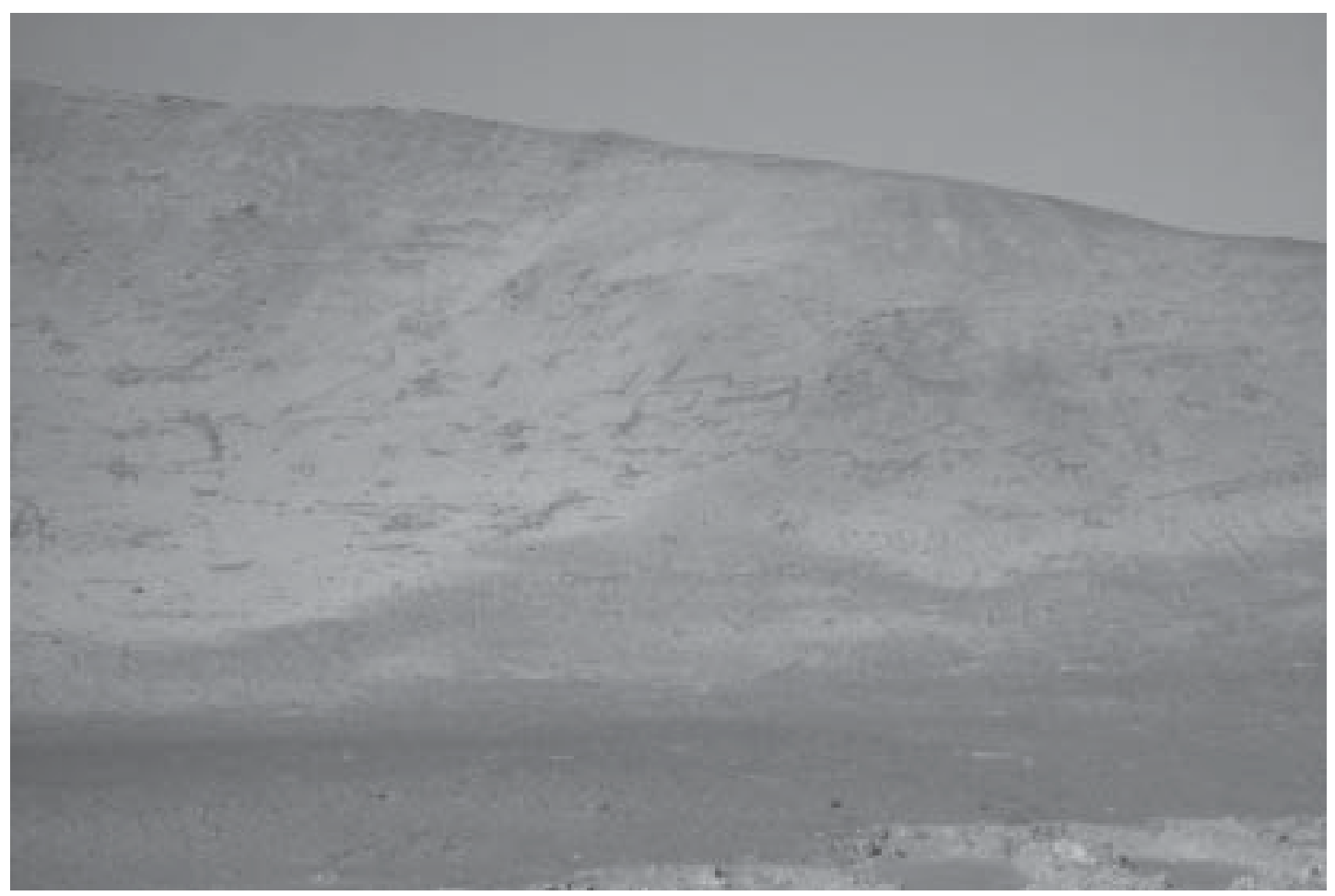

Figura 20. Geoglifos de Salar de Soronal.

Geoglyphs, Salar de Soronal.

Sector ex estación ferroviaria Aguada (5.1 $)^{5}$ (UTM 398500 E - 7721944 N; 815 msm)

Los geoglifos se ubican por el borde suroeste del cerro Soronal, orientados al este y sureste, por donde cruzan los senderos que provienen del sector Aguada, rumbo a la costa. Aquí se reiteran los diseños ya conocidos; se identifican las grandes figuras geométricas y un "antropomorfo" del estilo Cerros Pintados.

Así, sitios que parecieran tan inconexos entre sí, en el extenso desierto tarapaqueño se integran por complejos sistemas de rutas, hasta alcanzar su convergencia en el hospitalario salar de Soronal. Por lo tanto, la orientación de los geoglifos define visiblemente la intención en el sentido que fuese reconocido por los caravaneros a través de la ruta que los conducía a la costa, una vez logrado el descanso en las paskanas de Soronal.

\section{Sector cementerio cristiano (5.2) ${ }^{5}$ (UTM 398127} E - $7724476 \mathrm{~N} ; 750 \mathrm{msm}$ )

Los geoglifos se localizan en el cerro del noreste del salar y se orientan al oeste, en un tramo aproximado de $500 \mathrm{~m}$ en sentido norte sur. Sus diseños muestran rasgos del estilo Cerros Pintados, con sus característicos cuerpos de lados cóncavos.

Sector Alto Soronal este $(5.3)^{5}$ (UTM 398548 E $7725456 \mathrm{~N}$; $850 \mathrm{msm}$ )

Los geoglifos se localizan sobre suaves lomas de una quebradilla o encañada asociados a un sendero que conecta el salar de Soronal y el salar Santa Lucía. Estas rutas cruzan diagonalmente el territorio articulando puntos tan distantes como Tarapacá, Mamiña, Macaya y otros oasis de la precordillera, con sectores de La Noria-Rinconada, Yungay Bajo y salar de Santa Lucía, en su ingreso a la cordillera de la costa, para culminar en la costa al sur de Iquique (Figura 1).

Sector cerro San Luis sureste $(5.4)^{5}$ (UTM 399472 E - 7722335 N; 790 msm)

Aquí los geoglifos se orientan al sur marcando la entrada o salida del salar de Soronal. La ruta caravanera más importante rodea la base del cerro San Luis bifurcándose en dos, una hacia el oeste 


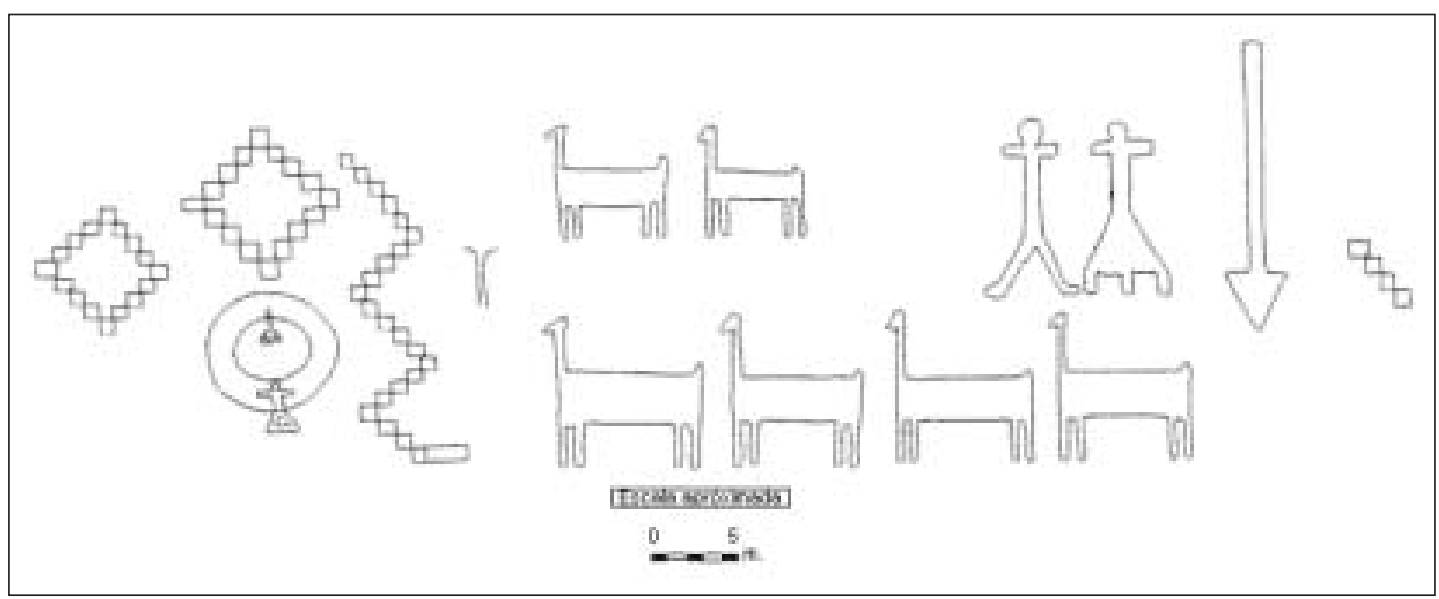

Figura 21. Geoglifos geométricos y zoomorfos, sitio Alto Barranco (dibujo de L. Briones 1968). Geometric and zoomorphic geoglyphs, Alto Barranco (drawing by L. Briones 1968).

(la Aguada) y la otra, remonta el "abra" para culminar en pleno salar, frente al principal sector de geoglifos del sector Aguada. Aquí se intensifica la presencia de los "círculos" vinculados a la cercanía de aguadas, pozos y ojos de agua.

\section{Sector cerro Soronal noroeste $(5.5)^{5}$ (UTM $395000 \mathrm{E}-7725500 \mathrm{~N} ; 820 \mathrm{msm}$ )}

Aquí los geoglifos se orientan al este y se ubican en la sección baja de la ladera de cerro Soronal $(1.365 \mathrm{msm})$. Es el sector menos denso, ya que la concentración de geoglifos se localiza por donde logísticamente ocurre el movimiento caravanero, esto es, por el borde oriental del salar, con entradas y salidas por los extremos sur y norte, respectivamente (abras de cerro Angostura y cerro Camello).

\section{Alto Barranco o Alto Caramucho (3.0) ${ }^{5}$ (UTM 379940 E - $7717305 \mathrm{~N} ; 710 \mathrm{msm}$ )}

Por el sendero ancho que cruza el abra del suroeste del salar de Soronal en dirección a la costa, se interpone una suave serranía mostrando hacia el este un panel con geoglifos (UTM 389495 E 7714598 N) advirtiendo simbólicamente el último tramo que resta para alcanzar la costa. Son siete figuras geométricas destacando el "rombo", rodeado de "cruces de lados iguales". Desde este sector, el sendero se aproxima al borde occidental de la cordillera de la costa, lo que permite al viajero enfrentarse a un amplio sector del litoral. Es un paso natural por donde se descuelgan los senderos has- ta alcanzar las caletas de Barranco, Caramucho, Yape, Cáñamo, Patillos y Patache. Un aspecto clave, en la elección de este descenso al litoral, es la existencia de una aguada aún vigente (Núñez y Varela 1967; Núñez 1976).

Aquí se reconocen 18 figuras distribuidas en el sector medio e inferior de la colina, orientadas al norte, al oeste y este, respectivamente. Resaltan el "rombo escalerado" y una "doble hilera de llamas" acompañada por dos "personajes o guías", que subrayan la idea del tráfico caravanero (Figura 21), testimoniado por los senderos que pasan a través del "abra" y por un costado de la aguada. Quizás sea este recurso el que haya estimulado la elaboración de "círculos", orientados al este, los que parecen dar los auspicios para los caravaneros que acaban de alcanzar el litoral desde lo alto. Cierra el panel, por el extremo oeste, un geoglifo geométrico "flecha simple" (Figura 21).

\section{Discusión y Conclusiones}

A lo largo de la transecta caravanera estudiada de $150 \mathrm{~km}$, se identificaron rutas y geoglifos asociados con estaciones de tráfico o paskanas, estructuras de corrales y registros funerarios, vinculados con tráfico caravanero de larga distancia. De acuerdo a las dataciones de radiocarbono obtenidas de los contextos descritos, nos permite una primera aproximación cronológica de la elaboración de los geoglifos.

Se identificaron siete sitios con geoglifos de este a oeste: El salto, Santa Rosita, Cerros Pinta- 
dos, Pan de Azúcar, cerro Mono, salar de Soronal y Alto Barranco, articulados por rutas del patrón "rastrillo" y por senderos menores y pasajes ritualísticos en torno a los geoglifos. Además de la identificación y excavación de cuatro paskanas y dos registros funerarios, demostrándose que existían conexiones entre los asentamientos pecuarios y agrarios estables del interior con aquellos del litoral. Del total de los geoglifos documentados en el transecto (sobre 500 figuras individuales), se desprende que el patrón Cerros Pintados, caracterizado por los tipos 100 al $108^{7}$, está presente en un $10 \%$ a través de todos los sitios, otorgándole unidad y contemporaneidad al trazado de las rutas, sus ritos y al propio flujo caravanero.

De acuerdo a las dataciones obtenidas, junto a las comparaciones iconográficas, los geoglifos podrían datar desde los primeros eventos Formativos. Sin embargo, su clímax y máxima dispersión habrían ocurrido durante el desarrollo del complejo Pica-Tarapacá, entre los 900-1.450 años d.C., permeado más tardíamente por las interdigitaciones caravánicas altiplánicas a través del componente Saxamar (Núñez 1962,1966,1985a). Aunque no se segregan temas directamente vinculados con componentes altiplánicos e Inca.

La identificación de cerámica del complejo Pica-Tarapacá, en las rutas del transecto estudiado como de aquellas revisadas desde Quillagua hasta la quebrada de Tarapacá, asociadas a geoglifos, dan cuenta de la intensificación del uso de las rutas en una escala regional significativa. Por otro lado, las comparaciones estilísticas se observan más nítidamente con la materialidad cultural de dicho periodo. Por supuesto que estos eventos tardíos preinca de intensificación caravanera no excluyen evidencias más tempranas.

En efecto, la presencia en cerro Mono de una tumba datada a los $3.110 \pm 40$ años a.p., demostraría que, antes de los geoglifos locales, ya existían rutas iniciadas por grupos costeros. Estos se desplazaban hacia enclaves de los bosques del Tamarugal y oasis aledaños, tras la explotación complementaria de madera, alimentos de oasis, vegetales para artesanías y material lítico. Se repetiría aquí el patrón de explotación de oasis interiores al litoral, tal como ocurrió con las ocupaciones arcaicas costeras en el oasis de Tiliviche (Núñez 1985a, Standen y Núñez 1984) y Conanoxa (Schiappacasse 1995). El traslado de grupos familiares con niños fallecidos en la ruta (cerro Mono) indicaría que estos viajes y el acceso a los recursos interiores perduraban por temporadas, tal vez en la estación de verano, durante la mayor disponibilidad de productos de la tierra.

El acercamiento cronológico efectuado a lo largo de la transecta, probó la factibilidad de obtener dataciones absolutas de algunas evidencias relacionadas con los pasajes ritualizados (geoglifos): paskanas, depósitos de desperdicios, entierros humanos y asentamientos. La datación de un marlo de maíz en la paskana de Cerro Pintados 3, de 970 \pm 50 años a.p., indicaría que, desde los inicios del Desarrollo Regional, los geoglifos de Cerros Pintados ya eran parte de los ritos del tráfico regional. En el caso de Pan de Azúcar la datación de un marlo de maíz, de $450 \pm 40$ años a.p., daría cuenta de un evento caravanero tardío, en las postrimerías del Desarrollo Regional. Por otra parte, la muestra de carbón obtenida del principal campamento localizado frente a los geoglifos del salar del Soronal desde el nivel intermedio-inferior, y por lo tanto posterior al comienzo de ocupación, de $1.450 \pm 40$ años a.p., obtenida precisamente de un sector con superposición de estilos de geoglifos, podría admitir el carácter más temprano de ciertos conjuntos.

Con estas dataciones absolutas, es posible proponer en forma preliminar que entre los 540 a los 1.490 años d.C., el tráfico caravanero y su ritualística transdesértica logran su mayor irradiación, toda vez que las muestras provienen de las únicas ocupaciones identificadas junto a los geoglifos en el área más inhóspita y despoblada del desierto Tarapaqueño.

La presencia en cerro Mono de otro contexto funerario costeño (no datado), asociado a tiesto cerámico, significaría que esta ruta era utilizada hasta el nivel de Pampa del Tamarugal, por agrupaciones costeras. En efecto, el registro de semillas de algarrobo es un indicador de que estos contactos con los recursos complementarios, como los algarrobales interiores, ocurrían a través de estos pasajes de interacción interétnico. El acceso a la obtención de frutos y maderos para el profuso utillaje utilizado en el litoral, transformó a los bosques del Tamarugal en un territorio de explotación multiétnica, tanto desde las ocupaciones aldeanas de los oasis como desde los campamentos de pescadores en el litoral.

Por otro lado, las dataciones de fogones, en los niveles inferiores de las paskanas de Cerros Pintados, entre los 10.000-6.000 años a.p., indicarían que 
el mayor régimen de humedad, en el borde sur del salar de Pintados, habría creado un ambiente favorable en términos de vegas y vertientes. Por otro lado, la cercanía a los bosques de prosopis convirtió a este sector en un referente de refugio y subsistencia, durante el arcaico Tardío y eventos formativos costeros, iniciándose antes de los geoglifos el trazado de las primeras rutas transdesérticas.

Puesto que el espacio de distribución de la mayor frecuencia de los geoglifos coincide con el desierto arreico, la carencia de cursos fluviales entre los asentamientos estables piemontanos y el litoral, dio lugar a una red de senderos y paskanas por territorios abiertos y estériles (Briones y Chacama 1987). Entre estos despoblados se elaboraron durante las jornadas del tráfico de larga distancia estos iconos compartidos y comprendidos por todos los grupos caravaneros, dispuestos para augurar el buen desenlace de estas largas travesías transdesérticas. En este sentido, abras, rutas, paskanas, cerros sagrados, cargas y la recua en acción o pasiva (descanso y abrevaje), eran los únicos referentes de los caravaneros en el contexto de rituales y rogativas, en espacios donde la recua va inmersa en un inmenso despoblado, como una animación solitaria.

Esta expresión rupestre fue una solución monumental, dada la escala espacial y el manejo de visuales extensas, con símbolos, que respondían a la ideología del tráfico caravanero, elaborados por especialistas tanto en el oficio como en el culto entre los grupos que se atrevían a internarse por el desierto tarapaqueño. El amplio espacio estéril y sus paisajes inconmensurables fueron suficientes para incentivar la creación de imágenes identitarias, como un código ritualístico de caravaneros del desierto.

La dinámica de estas relaciones macroespaciales permitió afianzar el desarrollo cultural y económico de la sociedad tarapaqueña, y en este aspecto, el oficio y las redes caravaneras desempeñaron un rol significativo. El traslado e intercambio de bienes entre los valles, oasis, litoral y alti- plano, a través del tráfico caravanero, implicó no sólo transacciones económicas, sino también la generación de complejos procesos de la visualización del poder, creatividad simbológica, ritualidad compartida e integración de territorios étnicos vecinos. Las conexiones en términos de rutas y caravaneo con el altiplano meridional, requieren aún de mayor investigación, de modo que, y de acuerdo a las evidencias arqueológicas, el tráfico de grupos del complejo Pica-Tarapacá fue el responsable de la iconografía y del sistema vial orientado hacia los recursos del transecto descrito. El espacio articulado entre distintos enclaves sociales, económicos y ecológicos de la transecta se considera mutuamente complementario, acorde a los ideales de interacción caravanera del área centro-sur andina (Núñez y Dillehay 1979).

Finalmente, para probar la viabilidad de este transecto caravanero y para comprender los procedimientos logísticos y ritualísticos del caravaneo de larga distancia, se organizó junto a dos familias aymaras, durante 12 días, una reconstitución etnográfica con el manejo de una recua de quince llamas cargadas ${ }^{2}$. A través del perfil: salar del Huasco-Pica-Cerros Pintados-Pan de Azúcar-cerro Mono-salar de Soronal-Alto Barranco, se observó no sólo la factibilidad del traslado, sino la eficiencia de la organización del espacio y sus recursos por la misma ruta de los geoglifos.

Agradecimientos: Este trabajo es el resultado del Proyecto FONDECYT 3646-97, con el patrocinio del Departamento de Antropología de la Universidad de Tarapacá y del Instituto de Investigaciones Arqueológicas de la Universidad Católica del Norte. Igualmente nuestro agradecimiento a Rául Rocha U. por su participación como dibujante; a los evaluadores anónimos que con sus observaciones y sugerencias contribuyeron a mejorar la versión original y, finalmente, al equipo de la revista Chungara.

\section{Referencias Citadas}

Arriaza, B.; M. Allison; V. Standen; G. Focacci y J. Chacama 1986 Peinados Precolombinos en momias de Arica. Chungara 16-17:353-375.

Berenguer, J.

1994 Asentamientos, caravaneros y tráfico de larga distancia en el norte de Chile: El caso de Santa Bárbara. En De Costa a Selva: Intercambio y Producción en los Andes Centro Sur, editado por M.E. Albeck, pp.17-50. Buenos Aires: Instituto Interdisciplinario Tilcara, Universidad de Buenos Aires. 1995 Impacto del caravanero prehispánico tardío en Santa Bárbara. Hombre y Desierto 9:185-202.

1998a Identificación de camélidos en el arte rupestre de Taira: ¿Animales silvestres o domésticos? Chungara 28:85-114. 
1998b La iconografía del poder en Tiahuanaku y su rol en la integración de zonas de frontera. Boletín del Museo Chileno de Arte Precolombino 7:19-37.

2004 Caravanas, Interacción y Cambio en el Desierto de Atacama. Ediciones Sirawi, Santiago de Chile.

Bird, J.

1943 Excavations in the Northern Chile. Anthropological papers of the American Museum of Natural History Vol. 38:173-318. N.Y.

Bollaert, W.

1975 (1860) Descripción de la provincia de Tarapacá. Introducción, notas y traducción de Horacio Larraín B. Norte Grande 3-4:459-479.

Briones, L.

1984 Fundamentos para una metodología aplicada al relevamiento de los geoglifos del norte de Chile. Chungara 12:41-56.

1985 Definición y comportamiento estilístico de los geoglifos de Cerros Pintados. En Estudios en Arte Rupestre, editado por J. Aldunate, J. Berenguer y V. Castro, pp. 417418. Museo Chileno de Arte Precolombino. Santiago.

1987 Codificación y tipología de geoglifos del norte de Chile (Manuscrito en posesión del autor).

Briones, L. y J. Chacama

1987 Arte Rupestre de Ariquilda: Análisis descriptivo de un sitio con geoglifos y su vinculación con la prehistoria regional. Chungara 18:15-66.

1994 Rutas y sistemas de arte rupestre en el desierto tarapaqueño (Manuscrito en posesión de los autores).

Briones, L. y L. Núñez

2000 Inventario y catastro de sitios con geoglifos del norte de Chile (Manuscrito en posesión de los autores).

Clarkson, $\mathrm{P}$.

1998 Técnicas de determinación de las edades cronológicas de geoglifos. Chungara 28:419-460.

Clarkson, P. y L. Briones

2001 Geoglifos, senderos y etnoarqueología de caravanas en el desierto chileno. Boletín del Museo Chileno de Arte Precolombino 8:35-45.

Chacama, J. y L. Briones

1997 Arte Rupestre en el desierto Tarapaqueño, Norte de Chile. Boletín SIARB 10:41-51.

2003 El juego de la Falcónida. Boletín Sociedad Chilena de Arqueología 35-36:81-85.

Dorn, R.

1989 Cation-ratio dating of rock varnish: A geographic assessment. Progress in Physical Geography 13:559-596.

Galdames, L.

1990 Apacheta: La ofrenda de piedra. Diálogo Andino 9:11-25.

Gordillo, J.

1992 Petroglifos y Tráfico: Un caso de interacción microregional en el ámbito de los valles de Tacna, Perú. Boletín SIARB 6:54-62.

Gundermann, $\mathrm{H}$.

1984 Ganadería aymara, ecología y forrajes: evaluación regional de una actividad productiva andina. Chungara 12:99-124

Flores, J. y K. MacQuarrie

1994 Pastoreo contemporáneo: Un legado andino que persiste. En Oro de los Andes. Las Llamas, Alpacas, Vicuñas y Guanacos de Sudamérica, editado por J. Flores Ochoa, K. MacQuarrie y J. Portús, Volumen II, pp.101-193. Barcelona: Jordi Blasi.
Munizaga, J.

1980 Esquema de la antropología física del norte de Chile. Chungara 6:124-136.

Muñoz, I. y L. Briones

1998 Poblados, rutas y arte rupestre precolombino de Arica: Descripción y análisis de sistema de organización. Chungara 28:47-84.

Nielsen, A.

1997-98 Tráfico de caravanas en el sur de Bolivia: Observaciones etnográficas e implicancias arqueológicas. Relaciones de la Sociedad Argentina de Antropología, Tomo XXIIXXIII:139-178.

Niemeyer, $\mathrm{H}$.

1959 Excavaciones en Pica (provincia de Tarapacá). Publicaciones del Museo y la Sociedad Arqueológica de La Serena. Boletín 10:59-68.

1963 Nuevas excavaciones en Pica. Cementerio de Santa Rosita. Publicaciones del Museo y de la Sociedad Arqueológica de La Serena. Boletín 12:7-17.

Núñez, L.

1962 Contactos culturales prehispánicos entre la costa y la subcordillera andina. Boletín de la Universidad de Chile 31:42-47.

1963 Prospección arqueológica en la provincia de Tarapacá. Noticiario Mensual, Museo Nacional de Historia Natural año VIII No 85-86:1-9.

1966 Arqueología del rectángulo Loa-Camiña: Contextos y secuencias culturales. Actas del XXXVII Congreso de Americanistas, pp.145-182, Mar del Plata.

1976 Geoglifos y tráfico de caravanas en el desierto chileno. En Homenaje al Dr. R.P. Gustavo Le Paige, editado por H. Niemeyer, pp. 147-201. Universidad del Norte, Antofagasta.

1982 Asentamientos de cazadores-recolectores tardíos de la Puna de Atacama: Hacia el sedentarismo. Chungara 8:137-164.

1984 El Asentamiento Pircas: Nuevas evidencias de tempranas ocupaciones agrarias en el norte de Chile. Estudios Atacameños 7:152-177.

1985 a Tráfico de Complementariedad de Recursos entre las Tierras Altas y el Pacífico en el Area Centro Sur Andina. Tesis Doctoral. Departamento de Antropología, Universidad de Tokio.

1985b Petroglifos y tráfico de caravanas en el desierto Chileno. En Estudio en Arte Rupestre, editado por C. Aldunate, J. Berenguer y V. Castro, pp. 243-264. Museo Chileno de Arte Precolombino. Santiago.

Núñez, L. y L. Briones

1967 Petroglifos del sitio Tarapacá-47. Estudios Arqueológicos 3-4:43-75.

2003 Una caravana aymara actual por la ruta de los geoglifos del desierto tarapaqueño (Manuscrito en posesión de los autores).

Núñez, L., I. Cartajena, J. Loo, S. Ramos, T. Cruz y H. Ramírez 1997 Registro e Investigación del arte rupestre en la Cuenca de Atacama (Informe Preliminar). Estudios Atacameños 14:307-325.

Núñez, L. y T. Dillehay

1979 Movilidad Giratoria, Armonía Social y Desarrollo en los Andes Meridionales: Patrones de Tráfico e Interacción Económica. Universidad Católica del Norte, Antofagasta. 
Núñez, L. y J. Varela

1961-64 Un complejo preagrícola en el salar de Soronal (Cordillera de la Costa, Norte de Chile). Revista de Antropología del Instituto Nacional de Córdoba, Tomo IIIII:89-204.

1967 Sobre los recursos de agua y el poblamiento prehispano de la costa del norte de Chile. Estudios Arqueológicos 3-4:7-41.

Podestá, M. y D. Rolando

2001 Marcas en el Desierto. Arrieros en Ischigualasto (San Juan, Argentina). Boletín SIARB 15:63-68.

Santoro, C. y P. Dauelsberg

1985 Identificación de indicadores tempo-espaciales en arte rupestre del extremo norte de Chile. En Estudios en Arte Rupestre, editado por C. Aldunate, J. Berenguer y V. Castro, pp. 69-86. Museo Chileno de Arte Precolombino.

Schiappacasse, V.

1995 Utilidad del análisis comparativo del desecho lítico de varios sitios arcaicos de la quebrada de Camarones. Hombre y Desierto 9:29-34.

Soto, P.

1987 Evolución de deformaciones intencionales, tocados y prácticas funerarias en la prehistoria de Arica, Chile. Chungara 19:129-214. Arica, Chile.
Standen, V.G.

2003 Bienes Funerarios del Cementerio Chinchorro Morro 1: Descripción, Análisis e Interpretación. Chungara Revista de Antropología Chilena 35:269-274.

Standen, V. y L. Núñez

1984 Indicadores antropológicos-físicos y culturales del cementerio Tiliviche-2 (Norte de Chile). Chungara 12:135-153.

Standen, V.G., B.T. Arriaza y C.M. Santoro

1997 External auditory exostosis in prehistoric Chilean populations: a test of chronology and geographic distribution. American Journal of Physical Anthropology 103:119-129.

Van Hoek, M.

2004 The stepped fret motif in american rock-arte: An ttempt at tracing origin and meaning. The Artifact. Volume 42:75-91.

Yacobaccio, H.D.

1979 Arte rupestre y tráfico de caravanas en la Puna de Jujuy: Modelo e hipótesis. Ponencia Presentada a las Jornadas de Arqueología del Noroeste Argentino. Universidad de San Salvador, Buenos Aires.

Zlatar, V.

1984 Cementerio prehispánico Pica 8. Universidad de Antofagasta, Antofagasta.

Notas

1 Concepto dado por andinos y vallesteros para designar a la meseta precordillerana.

2 En mayo del año 2000 se realizó un documental a través del programa "Al sur del mundo" dirigido por Francisco Gedda. Se contó con la participación de dos familias aymaras, una de la comunidad de Llica (Bolivia) y otra de Pica (Chile), y con el asesoramiento científico de L.B. y L.N. coautores del artículo.

3 Método de fechado por acelerador de radiocarbono, basado en el cociente de cationes en artefactos de piedras barnizadas, que cubren las superficies intervenidas por los geoglifos, en contraste con las superficies no alteradas.

4 A raíz de los trabajos de conservación de los geoglifos del valle de Azapa en 1980, en el panel "la tropilla", se constató la existencia de falanges humanas y tres cuentas de collar de concha, evidencias del "huaqueo" de una tumba marcada por piedras, de las mismas que conforman los geoglifos inmediatos.

5 La numeración en paréntesis corresponde al número asignado al sitio con geoglifos, de acuerdo a las pautas convenidas por las investigaciones realizadas en la Universidad de Tarapacá y la Universidad Católica del Norte, entre 19751985 y continuado, hasta la fecha, en el "Inventario y Catastro de Sitios con Geoglifos del Norte de Chile" (Briones y Núñez 2000).

6 Vallesteros de Quisma y piqueños (Elba Morales, comunicación personal 1973) señalan que estos senderos se man- tuvieron vigentes hasta la década del cuarenta, cuando los comerciantes locales se movilizaban entre Pica y Ujina, este último, terminal del ferrocarril minero que unía Ollagüe y Calama.

7 La tipología aquí aplicada y en otras publicaciones del primer autor sobre el tema, es parte de otro estudio y catastro en proceso sobre los geoglifos del norte de Chile (Briones 1987).

8 En 1985 se hizo un primer sondeo estratigráfico en los depósitos de ceniza de CP-2.

9 Gentileza de la Dra. Betty Meggers (Smithsonian Institution).

10 Los cuerpos completos se han excavado en el cementerio Pica 8 (Núñez 1966; Zlatar 1984). Se trataría del guacamayo rojo (Ara chloroptera), conocido en Bolivia como Paraba roja.

11 Pez selacio marino, del suborden de los escuálidos, de cuerpo fusiforme y hendiduras branquiales laterales. La boca está situada en la parte inferior de la cabeza, arqueada en forma de media luna y provista de varias filas de dientes cortantes. Su tamaño varía entre cinco y nueve metros y se caracteriza por su voracidad.

12 Al igual que el resto de los geoglifos de Soronal, éstos se encuentran muy erosionados y semidestruidos por acción antrópica reciente, como es el caso del panel 6, afectado por la confección de pseudogeoglifos modernos, con diseños de tanques y círculos tizados, blancos de ejercicios militares ocurridos en décadas pasadas. 
